\title{
The utilisation of glutamine and glucose by a 3-D tumour model trapped in quiescence
}

\author{
${ }^{1}$ Hannah Smith, ${ }^{2}$ David De Souza, ${ }^{2}$ Dedreia Tull, ${ }^{2}$ Malcolm \\ McConville, ${ }^{1,3}$ Andrea Pellagatti, ${ }^{1,3}$ Jacqueline Boultwood, \\ ${ }^{1}$ Mary Board \& ${ }^{1,4^{*}}$ Richard Callaghan
}

1 Nuffield Department of Clinical Laboratory Sciences, Radcliffe Department of Medicine, University of Oxford, Oxford, UK

2 Metabolomics Australia, Bio21 Institute, University of Melbourne, Melbourne, Australia

3 NIHR Oxford Biomedical Research Centre Haematology Theme, Oxford, UK

4 Research School of Biology, and the Medical School, Australian National University Canberra, ACT 0200, Australia

Running Title:

The metabolic fate of glucose and glutamine in quiescent DLD1 spheroids

\section{To whom correspondence should be addressed:}

Richard Callaghan, Biomedical Science \& Biochemistry, Research School of Biology, Building 134, Linnaeus Way, The Australian National University Canberra, ACT 0200, Australia, Tel - +61 6125 0824; E-mail; richard.callaghan@anu.edu.au 


\section{ABSTRACT}

27 Solid tumours modify their metabolic strategy to ensure sufficient biomass and energy to maintain a high rate of proliferation. However, solid tumours are characterised by a high proportion of quiescent cells and little is known about their metabolic profile. A tumour spheroid model with DLD1 cells was used to investigate the influence of a quiescent state on the cellular utilisation of glucose and glutamine. Quiescent DLD1 spheroids displayed increased depletion of both nutrients from the bathing medium compared to their proliferative counterparts and displayed highly active overall metabolism. A combination of biochemical and metabolomics approaches demonstrated that glucose utilisation resulted in an increased production of the 3-carbon intermediates lactate and alanine in quiescent spheroids. In addition, glutamine metabolism was directed to anabolic pathways; including the "reverse TCA cycle" to produce citrate for fatty-acid synthesis. These metabolic adaptations in DLD1 spheroids may propose a metabolic altruism of quiescent regions in solid tumours to provide biosynthetic intermediates required to sustain tumour growth, angiogenesis and metastasis.

\section{Keywords:}

Tumour metabolism; glucose metabolism; glutamine metabolism; glycolysis; glutaminolysis; metabolomics; quiescence; tumour spheroid 


\section{INTRODUCTION}

The extensive alterations in the metabolic profile of cancer cells are now recognised as an addition to the hallmarks of cancer [1]. These alterations include high glucose consumption and its preferential metabolism via aerobic glycolysis, which produces lactic acid even in the presence of oxygen and fully functional mitochondria [2, 3]. Although the passage of pyruvate to the TCA cycle is depressed [2, 4], flux through oxidative phosphorylation is not negligible [5]. Glutamine enters the TCA cycle via $\alpha$ ketoglutarate $(\alpha-K G)$ and has multiple metabolic fates [6]. Metabolic adaptations enable preferential utilisation of glucose and glutamine to support the high rates of protein, lipid and nucleic acid synthesis that are required for rapid proliferation.

The consequence of high rates of proliferation, despite an insufficient vasculature and a lack of lymphatic drainage $[7,8]$, is the generation of a tumour microenvironment characterised by regions of hypoxia, nutrient deprivation, acidosis and high interstitial fluid pressure [9]. In turn, this hostile micro-environment leads to the development of distinct zones of proliferating, quiescent and necrotic cells within the tumour [10]. It is possible that tumour cells alter their metabolic strategies in response to the micro-environmental stresses in these different zones to promote cell survival. For example, hypoxia leads to inhibition of the cyclin dependent kinase inhibitors p27 and p21, which in turn depress cell proliferation [11-13], as do other microenvironment factors such as glucose deprivation and acidosis [2, 14]. Solid tumours contain a low fraction of proliferation competent cells [15] and the impetus for cells to assume a quiescent state is not fully understood. The presence of quiescent cancer cells is considered to have a major effect on tumour response to chemotherapy, particularly given that most drugs target the process of replication $[16,17]$.

The process of cell replication and division demands a sufficient supply of biomass and energy. By inference, this has led to the view that quiescent cells have a dramatically reduced metabolic rate compared to proliferating cells. However, Lemons and colleagues used a "contact inhibition" model in human fibroblasts to demonstrate that nutrient utilisation and the rates of pathways in central carbon metabolism are not significantly depressed in quiescence [18]. Moreover, they suggested that quiescent cells used the pentose phosphate pathway (PPP) to 
generate NADPH, which could be used for either detoxification of free radicals or biosynthetic purposes [18].

The majority of in vitro observations use monolayer cell cultures, which are not fully reflective of the complex architecture inherent to solid tumours, nor can they recreate the micro-environment influences [19].

Quiescence is induced by many factors from the tumour micro-environment [20], which are thought to induce multiple genetic changes [14]. Three experimental models of quiescence are used in vitro and involve, contact inhibition, mitogen/serum withdrawal or loss of adhesion. However, the three models do not elicit identical genetic changes or characteristic features [14]. The use of tumour spheroid, or organoid, culture systems provides a relatively simple model system to incorporate the complexities of 3-D tumour architecture. Investigations with proliferating and quiescent spheroids observed differences in glutamine metabolism [21]; in particular, the bifurcated fate of $\alpha-K G$ derived from glutamine. It was suggested that the coupling between carbon and nitrogen metabolism of glutamine is differentially regulated to meet the specific needs of proliferating and quiescent cells.

The contact-inhibition strategy to induce quiescence for 3-D cell culture systems leads to the formation of multiple "tissue zones" as previously demonstrated [17, 22, 23]. Attributing overall results to a specific cell state must take into account the confounding heterogeneity caused by the presence of proliferating, quiescent and necrotic zones. To achieve this, we have developed a fully reversible model of quiescence in tumour spheroids based on the serum withdrawal strategy [17]. This approach enables the generation of spheroids containing a homogeneous distribution of quiescent cells and an identical overall morphology/dimension to the proliferating counterpart. This enables improved discrimination and quantitative comparison.

The present investigation used a serum withdrawal method to detail the influence of a quiescent state on central carbon metabolism in tumour spheroids from DLD1 cells. Growth rates and expression of marker proteins for cell proliferation or quiescence were used to characterise the model system. Nutrient depletion from the bathing medium was correlated with the expression and activity of transporters and enzymes involved in metabolic pathways. Finally, a metabolomics approach 
112 determined the fate and metabolic strategies applied to the primary nutrients,

113 glucose and glutamine. The quiescent spheroids from DLD1 cells are metabolically

114 active and invoke a strategy geared to favour anabolic pathways. 


\section{EXPERIMENTAL}

\subsection{Materials}

The RPMI-1640 medium, foetal bovine serum and trypsin with EDTA were purchased from Invitrogen (Paisley, UK). The penicillin and streptomycin were from Lonza (Wokingham, UK). Protease inhibitors and glutamate pyruvate transaminase were from Roche (Mannheim, Germany). The DC detergent compatible protein assay and kaleidoscope precision plus protein standards were from Bio Rad Laboratories (Hercules, USA). The reduced and oxidised forms of $\beta$-Nicotinamideadenine dinucleotide and $\beta$-Nicotinamide-Adenine dinucleotide phosphate (NADP), the Glucose-6-phosphate Dehydrogenase, hexokinase, and NAD Lithium Salt were from Calbiochem - Merck Ltd (Nottingham, UK). EZ-Chemiluminescence Detection kit for HRP was from Geneflow Ltd. Primary antibodies (all raised in rabbit) to GLUT1 (H-43, cat. no. sc-7903), GLUT3 (H-50 cat. no. sc-30107), MCT1 (H-70 cat. no. sc50324), MCT4 (H-90), p27 (C-19 cat. no. sc-528) and c-Myc antibody HRP (A-14 cat. no. sc-789) as well as C-Myc overexpression 293T lysate were purchased from Santa Cruz biotechnology Inc. Primary antibodies to Glucose 6 phosphate dehydrogenase (cat no. ab993), glutamate dehydrogenase ([EPR11370], cat. no. ab168352), pyruvate kinase-HRP (cat. no. ab34554), hexokinase II (cat. no. ab37593) and lactate dehydrogenase-HRP ([EP1565Y] cat. no. ab208366) as well as secondary anti rabbit and anti-goat antibodies conjugated to HRP were from Abcam UK. The primary antibody to HIF-1a (IgG1-clone 54 cat. no. 610958) was from Becton Dickinson UK Itd. Primary antibodies to PFKP (cat. no. D2E5), and ASCT2 (G11, cat. no. 5100) were from New England Biolabs (Herts, UK). Primary antibodies to PFKL (cat. no. AV457740958) and PFKM (cat. no. SAB141) were from Sigma-Aldrich. (Dorset, UK). The primary antibody to Ki-67 (cat. no. M7240) and the polyclonal goat anti mouse HRP secondary antibody were from Dako,UK (Ely, UK). Normal horse serum and universal anti-mouse anti-rabbit secondary antibody for IHC were from Vector Laboratories Inc (California, USA). Novocastra Novolink polymer was from Leica biosystems. The $\left[5^{-}{ }^{3} \mathrm{H}\right]$ glucose was from PerkinElmer. $\left[{ }^{13} \mathrm{C}_{6}\right]$-glucose and $\left[{ }^{13} \mathrm{C}_{5}\right]$-glutamine were from Cambridge Isotope Laboratories (MA, USA). All other reagents were from Sigma-Aldrich (Dorset, UK). 


\subsection{Production of DLD1 tumour spheroids}

DLD1 human colon adenocarcinoma cells were grown as monolayers in RPMI-1640 as previously described [22]. DLD1 cells were obtained from Prof Roger Phillips from the Institute of Cancer Therapeutics (University of Bradford) and were routinely tested for Mycoplasma infection. The cells were not grown beyond passage 20 during this investigation.

Tumour spheroids (TS) were grown as suspension cultures from an initial seeding density of $2.5 \times 10^{5} \mathrm{cell} \mathrm{ml}^{-1}$ in $20 \mathrm{ml}$ and stirred at $55 \mathrm{rpm}$ (Techne MCS-104S) allowing spheroids to form, as previously described [17]. TS diameter was measured every 48-hour using a graduated calibrated microscope eyepiece graticule. TS

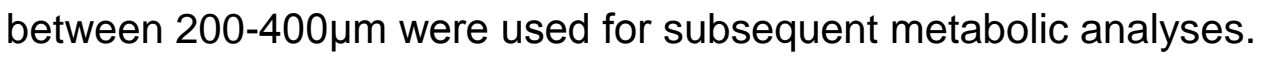

Homogenates were prepared from TS collected by gravity sedimentation and resuspended in homogenisation buffer $(0.05 \mathrm{M}$ Tris- $\mathrm{HCl}(\mathrm{pH} 8.0))$ and protease inhibitors. A glass homogenizer was used to disrupt TS structure and aliquots $(50 \mu \mathrm{l})$ were stored at $-80^{\circ} \mathrm{C}$. The protein concentration of TS homogenates was determined using the DC Brad (BioRad) protein assay according to the manufacturer's protocol.

\subsection{Generation of Quiescent TS $\left(T^{Q}{ }^{Q}\right)$}

TS from DLD1 cells were grown until they reached diameters of $200-400 \mu \mathrm{m}$ as described above. At this point the spheroids were exchanged into media supplemented with $0.1 \%(\mathrm{w} / \mathrm{v})$ fatty acid free BSA to replace the $10 \%(\mathrm{v} / \mathrm{v})$ foetal calf serum. The media was refreshed, every 48 -hour for seven days at which point the spheroids were harvested.

\subsection{Immunohistochemistry of TS}

TS were fixed, embedded and cut into $5 \mu \mathrm{m}$ sections as described [17]. Antigen retrieval was performed by incubating slides in buffer comprising $50 \mathrm{mM}$ Tris, pH 9.0 and 200 mM EDTA buffer, in a Decloaking chamber (Biocare Medical) at 25 p.s.i for 2 minutes. Slides were blocked with 2.5\% (v/v) horse serum (Vector Laboratories Inc, California, USA) prior to incubation with the primary monoclonal antibody to Ki67 (1:100) or p27 (1:150), for 1 hour at room temperature. Bound Ki-67 antibody was detected using an anti-mouse secondary whilst p27 bound antibody was detected 
using a Novolink polymer kit (Leica biosystems). Quantitation of immunohistochemistry sections was done manually. Individual sections were counted for the number of positive cells in a field/view. The number of positive cells were normalised per unit area $\left(\mu \mathrm{m}^{2}\right)$ as indicated in the figures. Quantitation was done for multiple independent sections taken from different spheroid preparations.

\subsection{Metabolic enzyme activity in Tumour Spheroids}

The activities of metabolic enzymes were measured using photometric assays on tissue homogenates (Hitachi Model U-2010 spectrometer). Full details of the assays and their optimisation to tumour spheroids have been described previously [24, 25]. Enzyme specific activity was then calculated from the initial rate of change of absorbance using the Beer Lambert law. The conditions for measurement of the activity of individual enzymes are detailed in a previous publication [26].

\subsection{Expression levels of metabolising enzymes and transporters in TS}

TS homogenates were mixed with reducing Laemmli sample buffer and heated at $95^{\circ} \mathrm{C}$ for 10 minutes. Homogenate proteins were separated by SDS PAGE and transferred to a nitrocellulose membrane. The membranes were blocked with $5 \%$ (w/v) skim-milk or BSA in PBS-T. The enzymes or transporters of interest were detected according to specific requirements of each antibody as described [26]. Following extensive washing, the immunoreactivity was assessed using the EZChemiluminescence kit. Representative blots for each of the transporters (Fig S1) and enzymes (Fig S2) are available in the supplementary data. Analyses of relative levels of expression were generated from densitometric analyses using the software Image $J$ obtained from multiple independent lysates. Blots contain positive control

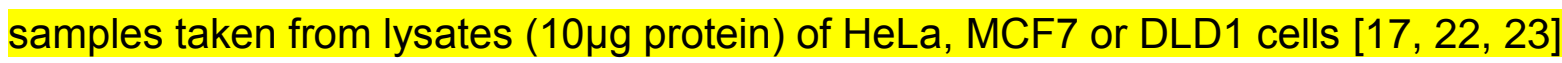
as indicated in the legend. Due to the varied and unpredictable effects of nutrient deprivation on protein expression, loading control for the SDS-PAGE was done using equivalent protein mass $(10 \mu \mathrm{g})$ in the lysates.

\subsection{Metabolite concentrations in the growth media}


Media samples were taken at defined time points during TS growth and stored immediately at $-20^{\circ} \mathrm{C}$. The levels of glucose, glutamine and lactate in the media at each time point were measured using spectrophotometric assays as previously described [26].

\subsection{Metabolomic analysis of glucose and glutamine fate in TS}

To analyse glucose utilisation, TS were exchanged into glucose, glutamine, phenolred and pyruvate-free DMEM medium. The serum free modified medium was supplemented with $1 \mathrm{~g} \mathrm{~L}^{-1}$ glucose and $2 \mathrm{~g} \mathrm{~L}^{-1}\left[{ }^{13} \mathrm{C}_{6}\right]$-glucose for $0.5,2$ or 24 hours prior to metabolite extraction.

To analyse glutamine utilisation, TS were exchanged into glucose, glutamine, phenol-red and pyruvate-free DMEM medium. The serum free modified medium was supplemented with $2 \mathrm{mM}$ glutamine and $1 \mathrm{mM}\left[{ }^{13} \mathrm{C}_{5}\right.$-glutamine] for $0.5,2$ or 24 hours prior to metabolite extraction.

Metabolic activity was quenched by rapidly cooling the culture flasks in an ethanol/dry-ice bath, excess medium removed and TS transferred to a pre cooled $2 \mathrm{ml}$ eppendorf tube. TS were then centrifuged at $10,000 \mathrm{~g}, 0^{\circ} \mathrm{C}, 30 \mathrm{sec}$ and washed 3 times in cold PBS, with repeated centrifugation to harvest the TS. Metabolites were extracted from the TS pellet with $50 \mu \mathrm{l}$ chloroform and $200 \mu \mathrm{l}$ of $3: 1 \mathrm{MeOH}: \mathrm{H}_{2} \mathrm{O}$ containing the internal standard adonitol (1.3nmoles). The tube was vortexed and incubated on ice for 15 min with occasional vortexing and sonication, prior to centrifugation $16,100 \mathrm{~g}, 0^{\circ} \mathrm{C}$ for $5 \mathrm{~min}$. The supernatant was then added to a fresh tube with $100 \mu \mathrm{l}$ double distilled $\mathrm{H}_{2} \mathrm{O}$, vortexed and centrifuged at $16,100 \mathrm{~g}, 0^{\circ} \mathrm{C}$ for 5 min the aqueous and organic phases were separated and stored at $-80^{\circ} \mathrm{C}$ before transfer to Metabolomics Australia for analysis by GC-Mass spectrometry.

Polar metabolites were prepared for ${ }^{13} \mathrm{C}$-metabolomics by $\mathrm{GC} / \mathrm{MS}$ analysis, then data analysed as described previously [27]. For ${ }^{13} \mathrm{C}$-labelling of total fatty acids, the organic phase for each sample was evaporated to dryness under vacuum, then resuspended into $45 \mu \mathrm{l}$ 2:1 chloroform:methanol $(\mathrm{v} / \mathrm{v})$. of Methprep II reagent $(5 \mu \mathrm{l})$ (Grace Alltech) was added to each sample and incubated at $37^{\circ} \mathrm{C}$ for 30 min with 
constant mixing at 750rpm. Methyl-esterified fatty acids (FAME) were analysed by GC/MS and the data analysed using the methods described previously [27].

\subsection{Gene expression profiling}

RNA was extracted from tumour spheroids using TRIZOL. For each sample, 100ng of total RNA was amplified and labelled with the 3' IVT Express Kit following the manufacturer's protocol (Affymetrix, Santa Clara USA). Biotin-labelled fragmented cRNA $(10 \mu \mathrm{g})$ was hybridised to GeneChip Human Genome U133 Plus2.0 Arrays (Affymetrix), which covers more than 47,000 transcripts representing 39,000 human genes. Hybridisation occurred at $45^{\circ} \mathrm{C}$ for $16 \mathrm{hr}$ in a Hybridisation Oven (Affymetrix). Chips were then washed and stained in a Fluidics Station 450 (Affymetrix) and scanned with a GeneChip Scanner (Affymetrix). Data was analysed using GeneSpring 7.3.1 software (Agilent) as previously described [28].

\subsection{Data Analysis}

Data analysis of TS growth and enzyme activity was performed using GraphPad Prism 5.0 (GraphPad Software Inc, La Jolla, CA). TS growth data was fitted with an exponential growth curve, $Y=A e^{K X}$, where $Y$ represents spheroid volume $\left(\mathrm{mm}^{3}\right)$ and $X$ signifies TS age (days). $Y$ begins at $A$ and increases exponentially with a rate constant $\mathrm{K}$.

Enzyme assays were analysed using linear regression analysis of the raw spectrophotometric data to give reaction rates. Enzyme activity was then calculated according to the Beer Lambert law and corrected for total protein concentration.

Western blots were analysed by densitometry using Image $\mathrm{J}$, raw data was normalised to give expression levels relative to the averaged densitometry observed in TS ${ }^{P}$ on each western blot. It is well established that changes in cell growth conditions may alter synthesis of "marker proteins" (e.g. $\beta$-actin) [29], rendering them ineffectual as loading controls for SDS-PAGE. Consequently, the sample loading was normalised according to the total protein amount loaded onto the gel, which represents the optimal method for the investigations in this study [30]. 
271 Enzymatic and expression data were compared using one-way ANOVA with the

272 Bonferroni's multiple comparison post-hoc test. All regression analysis and statistical

273 comparisons were done using GraphPad Prism 5.

274 Enzymatic/transporter activity assays were undertaken with lysates from TS

275 produced from different "mother dishes" and n-values represent independent

276 observations. Each n-value for metabolomic analysis was obtained from two spinner

277 flasks from a "mother dish". Where $n>1$, the "mother dishes" were generated on

278 different days and cell passage numbers; thereby generating independent

279 observations. 


\section{RESULTS}

\subsection{Growth characteristics of tumour spheroids in quiescence inducing conditions}

TS of DLD1 cells were grown in conventional medium for a period of 21 days and the diameters $(\phi)$ were measured every 48 hours to enable calculation of tissue volume. These spheroids were designated $\mathrm{TS}^{\mathrm{P}}$ and their change in volume over the 20 day period is shown in Figure 1a. Over this period the volume increased in an exponential manner from $0.0012 \pm 0.0003 \mathrm{~mm}^{3}(\phi=84 \pm 8 \mu \mathrm{m})$ to $0.40 \pm 0.07 \mathrm{~mm}^{3}(\phi=$ $886 \pm 64 \mu \mathrm{m})$. Spheroids were also grown in conditions of serum withdrawal to generate a reversible quiescent state as previously described [13] and will be referred to as $T^{Q}$ in this manuscript. The $\mathrm{TS}^{\mathrm{Q}}$ also started at $0.0012 \pm 0.005 \mathrm{~mm}^{3}$ volume, however, they only grew to $0.037 \pm 0.0003 \mathrm{~mm}^{3}(\phi=385 \pm 26 \mu \mathrm{m})$ in the 20 day period, which is a statistically significant $(P<0.001)$ reduction compared to the $\operatorname{TS}^{\mathrm{P}}$ (Figure 1a).

Several batches of $\mathrm{TS}^{\mathrm{Q}}$ were subjected to serum withdrawal for 10 days and then transferred to conventional, serum replete medium for a further 10 days. Upon addition of serum, the spheroids rapidly resumed growth in a similar manner to the TS $^{P}$ (Figure 1a). The rapid resumption of normal growth demonstrates that the quiescent state of the TS was a reversible one and the cells could rapidly resume proliferation.

Immunohistochemical (IHC) analysis was used to demonstrate the relative expression levels of proliferation and quiescence markers, as shown in Figure 2. Spheroids grown under serum withdrawal conditions were harvested at day 10 at which time they reached a diameter of $\phi=328 \pm 24 \mu \mathrm{m}$. The spheroids grown under conventional conditions $\left(\mathrm{TS}^{\mathrm{P}}\right)$ were harvested at day 3 and displayed a diameter $\phi=$ $385 \pm 42 \mu \mathrm{m}$. The use of $\mathrm{TS}^{\mathrm{Q}}$ and $\mathrm{TS}^{\mathrm{P}}$ with equivalent diameters ensured equivalent diffusion of oxygen and nutrients into the spheroids and similar elimination of toxic metabolites. When TS grow beyond $\phi \sim 500 \mu \mathrm{m}$, they naturally develop regions of quiescence, hypoxia and necrosis. Therefore, the use of spheroids with lower diameters ensured similar cellular characteristics throughout the tissue. 
The proliferative status of TS was assessed by expression of the nuclear marker protein Ki-67 (Figure 2a-c), which is expressed in all cell cycle stages other than quiescence. $\mathrm{TS}^{\mathrm{P}}$ displayed abundant $\mathrm{Ki}-67$ expression, which was localised throughout the tissue (Figure 2a), demonstrating an extensive and uniform distribution of proliferating cells. In contrast, $\mathrm{TS}^{\mathrm{Q}}$ showed a considerable reduction in the expression of this proliferation marker (Figure 2b), reflecting a marked depression in proliferative capacity. Quantitation was done for multiple independent TS preparations $(n=4)$ and as shown in Figure 2(c), the expression of Ki67 was significantly $(p<0.001)$ reduced in the quiescent spheroids $\left(T^{Q}\right)$.

The expression of the tumour suppressor gene product p27 is a marker for quiescence given its ability to slow or halt the cell cycle and was used to identify regions of quiescence in the TS. As shown in Figure 2d, there was negligible expression of $\mathrm{p} 27$ in $\mathrm{TS}^{\mathrm{P}}$, which complements the high level of Ki-67 staining. In complete contrast, the $T S^{Q}$ were characterised by strong expression and widespread distribution of p27 (Figure 2e), which complemented the low expression of Ki-67. The IHC data verifies the generation of quiescent tissue following growth of TS under conditions of serum withdrawal. Furthermore, quantitation was done for multiple independent TS preparations $(n=5)$ and as shown in Figure $2(f)$, the expression of the quiescence marker p27 was significantly increased $(p<0.001)$ in the TS ${ }^{Q}$.

The transcription factor c-Myc is constitutively expressed in cancer cells and provides a major impetus for proliferation. In particular, a number of metabolic pathways and their enzymes are affected by stabilised or elevated c-Myc expression. As shown in Figure $1 b$, the expression of $c-M y c$ in $\mathrm{TS}^{Q}$ was reduced $(\mathrm{P}<0.05)$ to $26 \%$ of the value seen in the TS ${ }^{P}$. A representative western immunoblot is found in Supplementary Figure 2. The "dampened" influence of c-Myc provides further proof of the quiescent nature of TS grown with serum withdrawal. This model has already been fully characterised [17] at all growth stages and the citation provides further assessments of growth parameters.

In summary, serum withdrawal generated a quiescent state that was observed throughout the tissue and the tissue could resume proliferation upon re-introduction of serum; thereby demonstrating tissue viability in the model of quiescence. 


\subsection{Comparison of glucose utilisation in proliferating and quiescent tumour spheroids}

$\mathrm{TS}^{\mathrm{Q}}$ and $\mathrm{TS}^{\mathrm{P}}$ were routinely grown in RPMI medium and the depletion of glucose from this medium (initial glucose concentration $=11 \mathrm{mM}$ ) was measured for 24 hours as shown in Figure $3 a$. By $24 \mathrm{hr}$, the $\mathrm{TS}^{Q}$ had depleted $546 \pm 98 \mu \mathrm{mol}\left(\mathrm{mg}\right.$ protein) ${ }^{-1}$ of glucose, which was approximately two-fold higher than the $292 \pm 98 \mu \mathrm{mol}$ (mg protein $)^{-1}$ observed for TS $\mathrm{S}^{\mathrm{P}}(\mathrm{P}<0.05)$. Protein expression levels for metabolic enzymes and transporters were measured with western immunoblotting and quantitated using Image $J$ software. Tables 1 and 2 display quantified data and Supplementary Figures 1 and 2 provide representative western blots for the transporters and enzymes.

Enhanced uptake into cells provides a possible mechanism to increase the depletion of glucose from surrounding medium. Glucose uptake into DLD1 cells will involve the GLUT 1 and GLUT 3 transporters, which are characterised by a high affinity $\left(K_{M} \sim 1 \mathrm{mM}\right)$ for glucose and under the growth conditions of this investigation (i.e. $11 \mathrm{mM}$ glucose) the transport rate would be near maximal. However, the mRNA and protein levels of both GLUT isoforms were decreased in $\mathrm{TS}^{\mathrm{Q}}$ compared to $\mathrm{TS}^{\mathrm{P}}$ (Table 1). Depletion of glucose from medium will also be under control of the hexokinase II enzyme in cancer cells. Hexokinase catalyses phosphorylation of hexoses in order to maintain a large concentration gradient for glucose into the cell. Despite lower expression of hexokinase II (Table 2), the overall metabolic activity for the enzyme was increased approximately two-fold in $\mathrm{TS}^{\mathrm{Q}}$ compared to $\mathrm{TS}^{\mathrm{P}}(\mathrm{P}<0.02)$. This increase in metabolic capacity is likely to be responsible for enhanced glucose depletion from the medium by $\mathrm{TS}^{\mathrm{Q}}$.

Cellular glucose has numerous fates and cancer cells adapt a metabolic strategy to produce lactate via aerobic glycolysis in preference to oxidative phosphorylation. Significant lactate production was observed in $\mathrm{TS}^{\mathrm{P}}\left(132 \pm 32 \mu \mathrm{mol} \mathrm{mg}^{-1}\right)$ in a 24 hour period as shown in Figure $3 \mathrm{~b}$. Moreover, the amount of lactate in the medium was 1.8-fold higher $(P<0.05)$ in $T S^{Q}$. Efflux of lactate from cells to the medium is mediated by the MCT4 transporter[31], whereas the MCT1 isoform is associated with flux in the opposite direction. Expression of MCT4 was retained in $\mathrm{TS}^{\mathrm{Q}}$; however, levels of MCT1 were markedly reduced $(P<0.001)$ compared to TS $($ Table 1$)$. 
The ratios of lactate release to the glucose depleted were similar between the two growth conditions: $\operatorname{TS}^{\mathrm{P}}\left(131 / 292 \mu \mathrm{mol} \mathrm{mg}^{-1}\right)=0.45$ versus $\mathrm{TS}^{\mathrm{Q}}\left(232 / 546 \mu \mathrm{mol} \mathrm{mg}^{-1}\right)$ $=0.42$. According to predictions from the "Warburg effect" the oxidation of glucose exclusively through glycolysis would produce a maximum of 2 moles of lactate per mole of glucose. These observations suggest that a significant fraction of the glucose was being diverted to alternate pathways.

To determine the fate of glucose, we generated a comparative metabolic profile between $T S^{Q}$ and $T S^{P}$ beginning with the expression and metabolic capacity of key glycolytic enzymes (Table 2).

The activity of PFK1 is considered a major determinant of flux through glycolysis and three isoforms are found in cancer cells. Levels of protein and mRNA demonstrated that the $\mathrm{M}$ - and L-isoforms of PFK1 were unaffected by quiescence, whereas the PFK1-P was reduced $(P<0.05)$ in $T^{Q}{ }^{Q}$ compared to $T^{P}$. The overall metabolic capacity of PFK1 in spheroid homogenates was $29.6 \pm 9.9 \mathrm{nmol} \mathrm{min}^{-1} \mathrm{mg}^{-1}$ in TS $\mathrm{TS}^{\mathrm{P}}$ and $69.3 \pm 17.8 \mathrm{nmol} \mathrm{min}^{-1} \mathrm{mg}^{-1}$ in quiescent tissue. This difference in activity did not reach statistical significance.

The final reaction of glycolysis is the conversion of PEP to pyruvate and is catalysed by pyruvate kinase (PK). The expression of PK was unaffected by the induction of a quiescent state in the spheroids as demonstrated by both mRNA and protein levels (Table 2). However, the metabolic capacity of PK was 2.1 -fold higher $(P<0.001)$ in quiescent tissue.

Does the expression and activity of lactate dehydrogenase (LDH) concur with the elevated rate of $\mathrm{PK}$ and higher lactate release from quiescent tissue? Indeed, the protein expression level for $L D H$ was increased 1.7 -fold $(P<0.01)$ in TS ${ }^{Q}$ (Table 2). This observation was in line with the 1.8-fold increase in the metabolic capacity of $\mathrm{LDH}(\mathrm{P}<0.005)$ observed with the quiescent tissue (Table 2$)$.

The increased glucose utilisation and lactate production in $\mathrm{TS}^{\mathrm{Q}}$ were supported by enhanced activity and/or expression of two key enzymes; PK and LDH. However, the ratio of lactate produced per glucose consumed suggested that the carbon skeleton was directed to multiple fates. The ultimate fate of carbons derived from glucose 
405

406

407

408

409

410

411

412

413

414

415

416

417

418

419

420

421

422

423

424

425

426

427

428

429

430

431

432

433

434

(and glutamine) were fully described using metabolomic analysis using isotopic tracers in proliferating and quiescent spheroids.

\subsection{Metabolomic analysis on the fate of ${ }^{13} C_{6}$-glucose in proliferating and quiescent tumour spheroids}

Spheroids were grown in medium supplemented with $\left[{ }^{13} \mathrm{C}_{6}\right]$-glucose and the incorporation of $\left[{ }^{13} \mathrm{C}\right]$-label into polar metabolic intermediates was measured using GC/MS. The metabolite profile was measured at 0.5, 2 and 24-hour following addition of $\left[{ }^{13} \mathrm{C}_{6}\right]$-glucose to the medium and the numeric values for each intermediate detected are shown in Supplementary Table 1. The enrichment of glycolytic intermediates (and alternate entry points for generating pyruvate) with $\left[{ }^{13} \mathrm{C}\right]$-label after 24-hour is depicted in Figure 4.

In both spheroid types, there was significant enrichment with $\left[{ }^{13} \mathrm{C}\right]$-label in the glycolytic intermediates and reflects the predominance of this pathway for the metabolism of glucose. By 24-hour, the $\left[{ }^{13} \mathrm{C}\right]$-label enrichment in lactate was higher in quiescent tissue (Figure 4). This is consistent with the increased production of lactate by $\mathrm{TS}^{\mathrm{Q}}$ observed with biochemical assays (Figure $3 \mathrm{~b}$ ). Lactate is formed by the reduction of pyruvate, a reaction catalysed by lactate dehydrogenase (LDH). However, pyruvate may be formed through multiple routes; for example, via decarboxylation of malate by the malic enzyme (ME). Another route involves the formation of PEP through the decarboxylation of oxaloacetate, an intermediate that may be derived from aspartate. As shown in Figure 4, both malate and aspartate display prominent enrichment with $\left[{ }^{13} \mathrm{C}\right]$-label and are possible sources for the production of lactate.

To ascertain the source of $\left[{ }^{13} \mathrm{C}\right]$-label enrichment in lactate, the fractional distribution of mass isotopomers was undertaken as shown in Figure 5. The mass isotopomers (m1-m3) indicate the number of $\left[{ }^{13} \mathrm{C}\right]$-labels in a specific metabolite and $m 0$ refers to the natural form not enriched with $\left[{ }^{13} \mathrm{C}\right]$. The data in Figure 5(a) also reveals the background levels of the naturally occurring $\left[{ }^{13} \mathrm{C}\right]$ (hashed bars). The lactate extracted from TS is overwhelmingly $m 3$, which can only be derived directly from the 
$\left[{ }^{13} \mathrm{C}_{6}\right]$-glucose precursor. Enrichment via malate/oxaloacetate could only produce $m 2 / m 1$-isotopomers, whose abundance were not different to background.

The continued oxidation of pyruvate is demonstrated by significant $\left[{ }^{13} \mathrm{C}\right]$-label enrichment in several TCA cycle intermediates as summarised by the schematic in Figure 6 (further details in Supplementary Table 1). The extents of labelling enrichment for fumarate, malate and citrate were in the range $25-35 \%$ and with no difference between quiescent and proliferating spheroids. There was a statistically significant, but low-magnitude, reduction of $\left[{ }^{13} \mathrm{C}\right]$-label enrichment in succinate in $\mathrm{TS}^{\mathrm{Q}}$ compared to $\mathrm{TS}^{\mathrm{P}}$. Mass isotopomer analysis of the metabolite citrate was used to determine the source of carbon entering the TCA cycle (Figure 5b). The citrate is predominantly $m 2$ in both $\mathrm{TS}^{Q}$ and $\mathrm{TS}^{\mathrm{P}}$, which indicates entry directly via acetyl-CoA.

Entry via carboxylation of pyruvate to OAA would have resulted in a significant fraction of the m3-isotopomer. A proportion of citrate was diverted to fatty acid synthesis as shown by the incorporation of $\left[{ }^{13} \mathrm{C}\right]$-label into several species after 24hour (Supplementary Table 1). The assimilation of these fatty acids into complex lipids is possible given the significant pool of glycerol-3-phosphate (Figure5), the precursor for glycerol synthesis.

There was also a significant enrichment of $\left[{ }^{13} \mathrm{C}\right]$-label in numerous amino-acids as shown in Figure 6 and Supplementary Table 1. The extent of label incorporation varied from less than $10 \%$ with glycine and serine, to $24-34 \%$ for glutamate, glutamine and aspartate; moreover, there were no differences between $\mathrm{TS}^{\mathrm{Q}}$ and TS $^{P}$. The most extensive incorporation of $\left[{ }^{13} \mathrm{C}\right]$-label into an amino-acid was found for alanine, which is primarily formed by transamination of pyruvate. Moreover, the extent of $\left[{ }^{13} \mathrm{C}\right]$-incorporation was significantly $(\mathrm{P}<0.01)$ higher for the quiescent compared to proliferating spheroids (Figure 6).

The data demonstrate that quiescent spheroids display high metabolic activity with a glucose fuel source that exhibits characteristic features of aerobic glycolysis, but with a clear involvement of more extensive mitochondrial oxidation. In general, the metabolic profile was similar between the proliferating and quiescent spheroids. However, the latter displayed a higher abundances of alanine and lactate, both of which are important anabolic precursors. 


\subsection{Utilisation and metabolic fate of glutamine in proliferating and quiescent tumour spheroids}

Glutamine is a versatile nutrient since its carbon-skeleton may be used to generate energy or anabolic precursors and the amino-group provides nitrogen for biosynthetic reactions. The extent of glutamine depletion over $24 \mathrm{hr}$ for TS grown under conditions that promote either proliferation or quiescence are shown in Figure 3c. TS ${ }^{P}$ had depleted the equivalent of $32.7 \pm 3.9 \mu \mathrm{mol} \mathrm{mg}^{-1}$ glutamine from the medium, which was significantly lower $(\mathrm{P}<0.01)$ than the $58.9 \pm 4.7 \mu \mathrm{mol} \mathrm{mg}^{-1}$ depleted by the $\mathrm{TS}^{\mathrm{Q}}$. Similar to the case with glucose, the quiescent spheroids displayed an enhanced extent and rate of glutamine depletion from medium; thereby demonstrating their metabolic vivacity. Uptake of glutamine into cancer cells is primarily mediated by the amino-acid exchanger ASCT2, which has high affinity for glutamine, but may also transport small neutral amino-acids. Measurement of both the mRNA and protein levels (Table 1) indicate that the induction of a quiescent state did not alter ASCT2 expression of in spheroids. The glutamate dehydrogenase enzyme mediates catalysis of the second reaction in the glutaminolytic pathway; namely, the deamination of glutamate to $\alpha$-ketoglutarate. Similarly, quiescence was not associated with alterations in either glutamate dehydrogenase protein expression or metabolic capacity (Table 2). Due to the intricate network of pathways linked to glutamine metabolism, there is no marker enzyme activity (or metabolite appearance) that can be used to reliably assign an overall flux rate. Consequently, a stable-isotope resolved metabolomics approach was used to determine the fate of glutamine and reveal the metabolic strategy underpinning its avid extraction from medium by quiescent spheroids.

\subsection{Metabolomic analysis on the fate of ${ }^{13} C_{5}$-glutamine in proliferating and quiescent tumour spheroids}

Spheroids grown under normal and serum depletion conditions were incubated with $\left[{ }^{13} \mathrm{C}_{5}\right.$ ]-glutamine for 24 hours followed by GC/MS analysis to detect metabolites enriched with $\left[{ }^{13} \mathrm{C}\right]$-label. Selected metabolic intermediates with detectable enrichment of $\left[{ }^{13} \mathrm{C}\right]$-label are depicted by the schematic shown in Figure 7, with full details available in Supplementary Table 2 . The greatest enrichment with $\left[{ }^{13} \mathrm{C}\right]$-label 
following $\left[{ }^{13} \mathrm{C}_{5}\right]$-glutamine supplementation was observed in TCA cycle intermediates and in several amino-acids. The metabolism of glutamine (glutaminolysis) is centred on the TCA cycle and forms a complex series of carbon flux in multiple directions.

Glutamate formed by the deamination of glutamine is converted to $\alpha-K G$ by two possible reactions; namely further deamination by glutamate dehydrogenase, or through a transamination pathway. Only low-level enrichment of $\left[{ }^{13} \mathrm{C}\right]$-label was observed in alanine, which suggests that the deamination route is preferred (Figure 7). The metabolism of $\alpha-K G$ may proceed in two directions, both within the TCA cycle. A significant proportion enters the TCA cycle in the normal direction (i.e. oxidative route) as observed by the extensive $\left[{ }^{13} \mathrm{C}\right]$-label enrichment in succinate, fumarate and malate (Figure 7). The mass isotopomer distribution for fumarate was measured (Figure $5 c$ ) and the predominant species is $m 4$, which is formed by passage of $\alpha-K G$ through the oxidative route of the TCA cycle. Malate produced by the oxidative route may leave the TCA cycle, enter the cytoplasm and produce pyruvate and NADPH for anabolic pathways. The extensive enrichment of $\left[{ }^{13} \mathrm{C}\right]$-label in aspartate (Figure 7) is indicative of substantive conversion of malate to OAA in the cytosol.

The reductive carboxylation route will result in the direct formation of citrate from $\alpha$ $\mathrm{KG}$ and this strategy is a precursor to fatty acid biosynthesis in cancer cells [32, 33]. The schematic in Figure 7 demonstrates significant label enrichment in citrate from $\left[{ }^{13} \mathrm{C}_{5}\right]$-glutamine. However, the enrichment data alone does not prove reductive carboxylation and the schematic shows that citrate may be enriched by $\alpha-K G$ proceeding in either the oxidative or reductive TCA cycle route. Mass isotopomer distribution for $\left[{ }^{13} \mathrm{C}\right]$-citrate demonstrated that both the $m 4$ (produced via the oxidative route) and $m 5$ forms (produced via the reductive route) were significantly above background levels (Figure $5 \mathrm{~d}$ ).

The mass isotopomer profile for $\left[{ }^{13} \mathrm{C}\right]$-enriched citrate also demonstrated a significant fraction of the $m 2$-form. This species will only occur should the labelled carbons exit the mitochondria to liberate acetyl-CoA for biosynthetic purposes. This was supported by the enrichment of $\left[{ }^{13} \mathrm{C}\right]$-label in several fatty acid species (Figure 7); moreover, the enrichment was higher for $\mathrm{C} 14: 0$ and $\mathrm{C} 16: 1$ species in the quiescent spheroids. 
531 Overall, the flux of ${ }^{13} \mathrm{C}_{5}$-glutamine was predominantly directed to the TCA cycle as

532 part of the glutaminolytic pathway. The enrichment of $\left[{ }^{13} \mathrm{C}\right]$-label from $\left[{ }^{13} \mathrm{C}_{5}\right]-$

533 glutamine into aspartate and citrate indicates substantive provision of anabolic

534 precursors. Furthermore, the higher enrichment into fatty acids demonstrates that

$535 \mathrm{TS}^{\mathrm{P}}$ have a greater tendency for increased biosynthetic reactions.

536 


\section{4. DISCUSSION}

538 DLD1 spheroids in a quiescent state display high metabolic activity, driven by the 539 avid consumption of glucose and glutamine from the bathing medium. The elevated 540 consumption of glucose is associated with increased lactate release compared to proliferating spheroids and thus commensurate with aerobic glycolysis common to cancer cells. Some of the pyruvate produced in glycolysis was further oxidised in the TCA cycle and a substantial amount was transaminated to the versatile metabolic precursor alanine in quiescent DLD1 spheroids. The consumed glutamine was directed towards biosynthetic pathways, in particular the synthesis of fatty acids. Overall, quiescent DLD1 spheroids maintain high rates of glycolytic activity with enhanced activities of glycolytic enzymes appear to promote a dynamic state of the glycolytic pathway with increased sensitivity to stimulation of biosynthetic pathways on resumption of proliferative activity. Increased lactate production promotes retention of the carbon skeleton derived from nutrients within the tumour microenvironment should the cells resume proliferation and it is possible that lactate carbon may be cycled through the pathway to enhance sensitivity. Alternatively, the quiescent DLD1 cells may be programmed to generate energy fuels or biosynthetic precursors for use in highly proliferative regions of a solid tumour. They certainly do not appear to be in metabolic stasis or a state of low activity.

Two previous investigations also compared rates of nutrient consumption and metabolic activity between quiescent and proliferative cells [18, 21]. One investigation used a simple 2-D monolayer culture [18] and the other involved tumour spheroids [21]. In both cases the generation of a quiescent state was not associated with reduced nutrient extraction from bathing medium. The two investigations used a contact-inhibition strategy to produce quiescence, which necessitated prolonged periods of cell growth and maintenance. Our model of quiescence did not require prolonged culture of DLD1 cells and in fact, the quiescent and proliferative spheroids were grown for identical periods. Moreover, the spheroid dimensions were similar and both conditions displayed homogenous cell distribution. We have previously demonstrated that prolonged culture $[17,22]$ leads to formation of spheroids with a heterogeneous distribution of proliferating, quiescent, hypoxic and necrotic cells. It is also important to note the distinct genetic profiles observed for the three commonly used models of quiescence [14]. These distinctions may account for the specific 
differences between investigations. However, all the studies agree that quiescent cancer cells are not metabolically inactive as has been the general premise. Our observations demonstrate that quiescent DLD1 spheroids elevate the storage (or efflux from cells) of carbon in 3-C molecules (i.e. alanine and lactate) and nitrogen that may be used for biomass production and nucleotide synthesis respectively. Indeed, increased expression of the MCT1 transporter during proliferation may allow re-uptake of the 3 carbon molecules and their use for biosynthesis. This increased biosynthetic capacity in DLD1 spheroids through higher metabolic activity provides a strategy to resume proliferation. Alternatively, our observations using DLD1 spheroids propose an altruistic role for quiescent cells to support other cells in a tumour mass that are involved in proliferation, angiogenesis and metastasis.

Metabolic co-operation in cancer is a well-established phenomenon and the tumour microenvironment has been termed an "ecosystem" [34]. For example, pancreatic stellate cells release alanine that is avidly taken up by the cancer cells and channelled to the mitochondria [35]. Mitochondrial alanine was demonstrated to drive the TCA cycle towards the synthesis of fatty acids for incorporation into lipids. The alanine is largely derived from stellate cells via autophagy and the authors contend that this carbon source reduces the dependence on glucose or glutamine [35, 36]. Similar tumour-host co-operation at a metabolic level have been observed between lung cancer cells and lung fibroblasts in vitro [37]. The cancer cells instigate reprogramming of fibroblast metabolism to elevate production of 3-carbon metabolites, and to ensure their availability by enhanced monocarboxylate transporter expression. The 3-carbon metabolites such as alanine, aspartate and proline provide a metabolically diverse set of benefits including precursors for fatty acid and ketone body synthesis and as nitrogen donors in several colorectal cancer cells [38], which are key factors in ensuring proliferative capacity.

Intra-tumour metabolic co-operation has also been observed primarily involving the shuttling of lactate between the hypoxic and normoxic cell populations [39, 40]. The energy deprived hypoxic cells generate substantial amounts of lactate, which is released to the tumour interstitium by the MCT4 transport protein [41]. The comparatively nutrient replete, and fully oxygenated, cells in the outer layers of a tumour take up the interstitial lactate via MCT1. The lactate is converted to pyruvate, 
602 which enters the TCA cycle as acetyl-CoA; thereby ensuring the carbon skeleton of

603 glucose may be fed into either oxidative or biosynthetic pathways.

604 Our data demonstrate that quiescent DLD1 cells display subtle alterations in their

605 metabolism to ensure the production of primarily 3-carbon intermediates and sources

606 of nitrogen. The data were determined using the DLD1 cell line and have similarities

607 to observations from other colon cancer lines and cells from other tissues. It is

608 possible that our observations provide a general feature of quiescent cancer tissue.

609 Nutrient recycling strategies are well-documented between tumours and stromal

610 tissue, immune and stem cell populations [34]. In addition, the efflux and uptake

611 systems for these intermediates are also adjusted between cell populations.

612 Consequently, these sources of fuel and anabolic precursors are readily available for

613 other cell populations within a tumour to maintain high rates of proliferation, to initiate

614 angiogenesis and to metastasise. Moreover, this symbiosis enables more efficient

615 utilisation of glucose and glutamine by surrounding proliferative cells that exist in a

616 perpetual balancing act between anabolic and energetic demands. 


\section{ACKNOWLEDGEMENTS}

$620 \mathrm{RC}$ wishes to acknowledge the assistance of Divya Muthiah with tissue culture and 621 tumour spheroid growth.

\section{COMPETING INTERESTS}

624 The authors declare that they have no competing interest with the contents of this 625 article.

\section{FUNDING}

Dr H Smith was funded by a Medical research Council D. Phil. Studentship (10CLS02JOB) awarded by NDCLS to undertake this research in the laboratory of A/Prof Callaghan. AP and JB acknowledge support from Blood Cancer UK. MB was supported by a Daphne Jackson Fellowship.

\section{AUTHOR CONTRIBUTIONS}

634 Hannah Smith, methodology, formal analysis, investigation, writing - review \& editing; David De Souza, conceptualisation, methodology, investigation, writing original draft; Dedreia Tull, resources, writing - review and editing; Malcolm McConville, resources, supervision, writing - review and editing, validation; Andrea Pellagatti, methodology, formal analysis, investigation, writing - review \& editing Jacqueline Boultwood, resources, supervision, writing - review and editing, validation; Mary Board, resources, investigation, supervision, writing - review and editing, \& Richard Callaghan, conceptualisation, methodology, resources, validation, supervision, writing - review and editing, project administration and funding acquisition. 
6461 Hanahan, D. and Weinberg, R. A. (2011) Hallmarks of cancer: the next 647 generation. Cell. 144, 646-674

6482 DeBerardinis, R. J., Lum, J. J., Hatzivassiliou, G. and Thompson, C. B. (2008) 649 The biology of cancer: metabolic reprogramming fuels cell growth and proliferation. 650 Cell Metab. 7, 11-20

6513 Warburg, O. (1956) On the origin of cancer cells. Science. 123, 309-314

6524 McFate, T., Mohyeldin, A., Lu, H., Thakar, J., Henriques, J., Halim, N. D., Wu, 653 H., Schell, M. J., Tsang, T. M., Teahan, O., Zhou, S., Califano, J. A., Jeoung, N. H., 654 Harris, R. A. and Verma, A. (2008) Pyruvate dehydrogenase complex activity controls metabolic and malignant phenotype in cancer cells. J Biol Chem. 283, 22700-22708 Saavedra, E. (2007) Energy metabolism in tumor cells. FEBS J. 274, 1393-1418 6 DeBerardinis, R. J., Mancuso, A., Daikhin, E., Nissim, I., Yudkoff, M., Wehrli, S. and Thompson, C. B. (2007) Beyond aerobic glycolysis: transformed cells can engage in glutamine metabolism that exceeds the requirement for protein and nucleotide synthesis. Proc Natl Acad Sci U S A. 104, 19345-19350 7 Brown, J. M. and Giaccia, A. J. (1998) The unique physiology of solid tumors: opportunities (and problems) for cancer therapy. Cancer Res. 58, 1408-1416 8 Leu, A. J., Berk, D. A., Lymboussaki, A., Alitalo, K. and Jain, R. K. (2000) Absence of functional lymphatics within a murine sarcoma: a molecular and functional evaluation. Cancer Res. 60, 4324-4327 9 Vaupel, P. (2004) Tumor microenvironmental physiology and its implications for radiation oncology. Semin Radiat Oncol. 14, 198-206 10 Sutherland, R. M. (1986) Importance of critical metabolites and cellular interactions in the biology of microregions of tumors. Cancer. 58, 1668-1680 Dang, C. V. (2001) Hypoxia inhibits G1/S transition through regulation of p27 expression. J Biol Chem. 276, 7919-7926 L. E. (2004) HIF-1alpha induces cell cycle arrest by functionally counteracting Myc. EMBO J. 23, 1949-1956 and Callaghan, R. (2005) The influence of tumour microenvironmental factors on the efficacy of cisplatin and novel platinum(IV) complexes. Biochem Pharmacol. 70, 1137-1146 Quiescence. PLOS Biology. 4, e83 
688

689

690

691

692

693

694

695

696

697

698

699

700

701

702

703

704

705

706

707

708

709

710

711

712

713

714

715

716

717

718

719

720

721

722

723

724

725

726

727

728

729

730

731

16 Jackson, R. C. (1989) The problem of the quiescent cancer cell. Adv Enzyme Regul. 29, 27-46

17 Mellor, H. R., Ferguson, D. J. and Callaghan, R. (2005) A model of quiescent tumour microregions for evaluating multicellular resistance to chemotherapeutic drugs. Br J Cancer. 93, 302-309

18 Lemons, J. M., Feng, X. J., Bennett, B. D., Legesse-Miller, A., Johnson, E. L., Raitman, I., Pollina, E. A., Rabitz, H. A., Rabinowitz, J. D. and Coller, H. A. (2010) Quiescent fibroblasts exhibit high metabolic activity. PLoS Biol. 8, e1000514

19 Thoma, C. R., Zimmermann, M., Agarkova, I., Kelm, J. M. and Krek, W. (2014) 3D cell culture systems modeling tumor growth determinants in cancer target discovery. Adv Drug Deliv Rev. 69-70, 29-41

20 Valcourt, J. R., Lemons, J. M., Haley, E. M., Kojima, M., Demuren, O. O. and Coller, H. A. (2012) Staying alive: metabolic adaptations to quiescence. Cell Cycle. 11, 1680-1696

21 Coloff, J. L., Murphy, J. P., Braun, C. R., Harris, I. S., Shelton, L. M., Kami, K., Gygi, S. P., Selfors, L. M. and Brugge, J. S. (2016) Differential Glutamate Metabolism in Proliferating and Quiescent Mammary Epithelial Cells. Cell Metab. 23, 867-880

22 Hall, M. D., Martin, C., Ferguson, D. J. P., Phillips, R. M., Hambley, T. W. and Callaghan, R. (2004) Comparative efficacy of novel platinum(IV) compounds with established chemotherapeutic drugs in solid tumour models. Biochemical Pharmacology. 67, 17-30

23 Walker, J., Martin, C. and Callaghan, R. (2004) Inhibition of P-glycoprotein function by XR9576 in a solid tumour model can restore anticancer drug efficacy. Eur J Cancer. 40, 594-605

24 Bloch, K., Smith, H., van Hamel Parsons, V., Gavaghan, D., Kelly, C., Fletcher, A., Maini, P. and Callaghan, R. (2014) Metabolic alterations during the growth of tumour spheroids. Cell Biochem Biophys. 68, 615-628

25 Board, M., Humm, S. and Newsholme, E. A. (1990) Maximum activities of key enzymes of glycolysis, glutaminolysis, pentose phosphate pathway and tricarboxylic acid cycle in normal, neoplastic and suppressed cells. Biochem J. 265, 503-509

26 Smith, H., Board, M., Pellagatti, A., Turley, H., Boultwood, J. and Callaghan, R. (2016) The Effects of Severe Hypoxia on Glycolytic Flux and Enzyme Activity in a Model of Solid Tumors. J Cell Biochem. 117, 1890-1901

27 Kowalski, G. M., De Souza, D. P., Burch, M. L., Hamley, S., Kloehn, J., Selathurai, A., Tull, D., O'Callaghan, S., McConville, M. J. and Bruce, C. R. (2015) Application of dynamic metabolomics to examine in vivo skeletal muscle glucose metabolism in the chronically high-fat fed mouse. Biochem Biophys Res Commun. 462, 27-32

28 Pellagatti, A., Cazzola, M., Giagounidis, A., Perry, J., Malcovati, L., Della Porta, M. G., Jadersten, M., Killick, S., Verma, A., Norbury, C. J., HellstromLindberg, E., Wainscoat, J. S. and Boultwood, J. (2010) Deregulated gene expression pathways in myelodysplastic syndrome hematopoietic stem cells. Leukemia. 24, 756-764 
29 Farmer, S. R., Wan, K. M., Ben-Ze'ev, A. and Penman, S. (1983) Regulation of actin mRNA levels and translation responds to changes in cell configuration. Mol Cell Biol. 3, 182-189

30 Gorr, T. A. and Vogel, J. (2015) Western blotting revisited: critical perusal of underappreciated technical issues. Proteomics Clin Appl. 9, 396-405

31 Dimmer, K. S., Friedrich, B., Lang, F., Deitmer, J. W. and Broer, S. (2000) The low-affinity monocarboxylate transporter MCT4 is adapted to the export of lactate in highly glycolytic cells. Biochem J. 350 Pt 1, 219-227

32 Gaglio, D., Metallo, C. M., Gameiro, P. A., Hiller, K., Danna, L. S., Balestrieri, C., Alberghina, L., Stephanopoulos, G. and Chiaradonna, F. (2011) Oncogenic KRas decouples glucose and glutamine metabolism to support cancer cell growth. Molecular systems biology. 7, 523

33 Ward, P. S., Patel, J., Wise, D. R., Abdel-Wahab, O., Bennett, B. D., Coller, H. A., Cross, J. R., Fantin, V. R., Hedvat, C. V., Perl, A. E., Rabinowitz, J. D., Carroll, M., Su, S. M., Sharp, K. A., Levine, R. L. and Thompson, C. B. (2010) The common feature of leukemia-associated IDH1 and IDH2 mutations is a neomorphic enzyme activity converting alpha-ketoglutarate to 2-hydroxyglutarate. Cancer Cell. 17, 225234

34 Icard, P., Kafara, P., Steyaert, J. M., Schwartz, L. and Lincet, H. (2014) The metabolic cooperation between cells in solid cancer tumors. Biochim Biophys Acta. 1846, 216-225

35 Sousa, C. M., Biancur, D. E., Wang, X., Halbrook, C. J., Sherman, M. H., Zhang, L., Kremer, D., Hwang, R. F., Witkiewicz, A. K., Ying, H., Asara, J. M., Evans, R. M., Cantley, L. C., Lyssiotis, C. A. and Kimmelman, A. C. (2016) Pancreatic stellate cells support tumour metabolism through autophagic alanine secretion. Nature. 536, 479-483

36 Kamphorst, J. J. and Gottlieb, E. (2016) Friendly neighbours feed tumour cells. Nature. 536, 401

37 Koukourakis, M. I., Kalamida, D., Mitrakas, A. G., Liousia, M., Pouliliou, S., Sivridis, E. and Giatromanolaki, A. (2017) Metabolic cooperation between cocultured lung cancer cells and lung fibroblasts. Laboratory Investigation. 97, 13211331

38 Krishnamurthy, R. V., Suryawanshi, Y. R. and Essani, K. (2017) Nitrogen isotopes provide clues to amino acid metabolism in human colorectal cancer cells. Scientific Reports. 7, 2562

39 Semenza, G. L. (2008) Tumor metabolism: cancer cells give and take lactate. J Clin Invest. 118, 3835-3837

40 McGillen, J. B., Kelly, C. J., Martínez-González, A., Martin, N. K., Gaffney, E. A., Maini, P. K. and Pérez-García, V. M. (2014) Glucose-lactate metabolic cooperation in cancer: insights from a spatial mathematical model and implications for targeted therapy. Journal of theoretical biology. 361, 190-203

41 Sonveaux, P., Végran, F., Schroeder, T., Wergin, M. C., Verrax, J., Rabbani, Z. N., De Saedeleer, C. J., Kennedy, K. M., Diepart, C., Jordan, B. F., Kelley, M. J., Gallez, B., Wahl, M. L., Feron, O. and Dewhirst, M. W. (2008) Targeting lactate- 
776 fueled respiration selectively kills hypoxic tumor cells in mice. J Clin Invest. 118, $777 \quad 3930-3942$ 


\begin{tabular}{|c|c|c|c|}
\hline \multirow{2}{*}{ TRANSPORTER } & \multirow{2}{*}{ ISOFORM } & \multicolumn{2}{|c|}{$\begin{array}{c}\text { EXPRESSION RATIO } \\
\left(T S^{Q} / T S^{P}\right)\end{array}$} \\
\hline & & mRNA & Protein \\
\hline Glucose transporter 1 (GLUT1) & SLC2A1 & $0.6(2)$ & $\begin{array}{c}0.47 \pm 0.08 \text { (4) } \\
P<0.02\end{array}$ \\
\hline Glucose transporter 3 (GLUT3) & SLC2A3 & $0.83(2)$ & $\begin{array}{c}0.68 \pm 0.09(7) \\
P<0.05\end{array}$ \\
\hline $\begin{array}{l}\text { Monocarboxylate transporter } 1 \\
\text { (MCT1) }\end{array}$ & SLC16A1 & $0.92(2)$ & $\begin{array}{c}0.30 \pm 0.04(5) \\
P<0.001\end{array}$ \\
\hline $\begin{array}{l}\text { Monocarboxylate transporter } 4 \\
\text { (MCT4) }\end{array}$ & SLC16A8 & $2.1(2)$ & $\begin{array}{c}0.82 \pm 0.09(7) \\
N S\end{array}$ \\
\hline Glutamine transporter (ASCT2) & SLC1A5 & $0.82(2)$ & $\begin{array}{c}1.07 \pm 0.17 \text { (9) } \\
N S\end{array}$ \\
\hline
\end{tabular}

\section{Table 1 The expression profiles of transporters associated with cellular metabolism in quiescent TS}

Tumour spheroids were grown under conditions that generated proliferative or quiescent tissue and following incubation, homogenates were prepared. The mRNA and protein expression levels were determined for metabolism associated transporters as described in the methods. Densitometric analysis was used to quantify the relative levels of protein obtained from western immunoblotting (see Supplementary Figure 1). Expression of protein and mRNA was normalised to the level found in proliferating spheroids, which were assigned a value of 1.0. The protein levels represent the mean \pm sem obtained from the number of 
independent samples indicated by the value in parentheses. A Student's t-test was used to determine whether differences in protein expression between $\mathrm{TS}^{\mathrm{P}}$ and $\mathrm{TS}^{\mathrm{Q}}$ were significantly different and $\mathrm{P}$-values are shown (NS indicates not significant) 


\begin{tabular}{|c|c|c|c|c|c|}
\hline \multirow{2}{*}{ ENZYME } & \multirow{2}{*}{ ISOFORM } & \multicolumn{2}{|c|}{$\begin{array}{c}\text { EXPRESSION RATIO } \\
\left(T S^{Q} / T S^{P}\right)\end{array}$} & \multicolumn{2}{|c|}{$\begin{array}{l}\text { MAXIMAL ACTIVITY } \\
\left(\text { nmoles } \mathrm{min}^{-1} \mathrm{mg}^{-1}\right)\end{array}$} \\
\hline & & mRNA & Protein & Proliferating & Quiescent \\
\hline Hexokinase & HK2 & $0.83(2)$ & $\begin{array}{c}0.57 \pm 0.19(11) \\
P<0.05\end{array}$ & $6.26 \pm 1.02(11)$ & $\begin{array}{c}12.1 \pm 2.3(5) \\
P<0.02\end{array}$ \\
\hline Phosphofructokinase1 & $\begin{array}{l}\text { PFK1-P } \\
\text { PFK1-M } \\
\text { PFK1-L }\end{array}$ & $\begin{array}{l}0.95(2) \\
1.08(2)\end{array}$ & $\begin{array}{c}0.53 \pm 0.06(3) \\
P<0.02 \\
1.28 \pm 0.22(16) \\
N S \\
1.03 \pm 0.21(7) \\
N S\end{array}$ & $29.6 \pm 9.9(4)$ & $\begin{array}{c}69.3 \pm 17.8(5) \\
N S\end{array}$ \\
\hline Pyruvate kinase & PK & $0.85(2)$ & $\begin{array}{c}1.51 \pm 0.20(8) \\
P<0.05\end{array}$ & $2155 \pm 258(5)$ & $\begin{array}{c}4490 \pm 320(6) \\
P<0.001\end{array}$ \\
\hline Lactate dehydrogenase & $\mathrm{LDH}$ & $0.63(2)$ & $\begin{array}{c}1.69 \pm 0.19(10) \\
P<0.01\end{array}$ & $1305 \pm 231$ & $\begin{array}{c}2318 \pm 158(6) \\
P<0.005\end{array}$ \\
\hline Glucose-6-phosphate dehydrogenase & G6P-DH & $1.08(2)$ & $\begin{array}{c}0.92 \pm 018(6) \\
N S\end{array}$ & $184 \pm 17(5)$ & $\begin{array}{c}252 \pm 35(9) \\
N S\end{array}$ \\
\hline Glutamate dehydrogenase & GLDH & - & $\begin{array}{c}1.03 \pm 0.157 \text { (8) } \\
N S\end{array}$ & $22.9 \pm 2.3(4)$ & $\begin{array}{c}22.9 \pm 4.0(4) \\
N S\end{array}$ \\
\hline
\end{tabular}


Table 2 The expression profiles and activities of cytosolic enzymes associated with cellular metabolism in quiescent TS Tumour spheroids were grown as proliferative or quiescent tissue and lysates or homogenates prepared to measure mRNA and protein expression. Protein expression levels were determined by Western Blot analysis (see Supplementary Figure 2). Expression of protein and mRNA was normalised to the level found in proliferating spheroids, which were assigned a value of 1.0. Activities of were measured from spheroid homogenates under conditions of high substrate concentration to provide the maximal enzyme activity. All values represent mean \pm sem from the number of independent preparations indicated in parentheses. Student's t-test analysis was used to determine differences in expression and activity between $\mathrm{TS}^{\mathrm{P}}$ and $\mathrm{TS}^{\mathrm{Q}}$ as indicated. NS indicates a nonsignificant difference. 


\section{FIGURE LEGENDS}

\section{Figure 1 General characteristics of DLD1 spheroids grown under conditions to induce quiescence}

Tumour spheroids of DLD1 cells were grown in media to generate proliferating or quiescent tissue.

(a) The volume of proliferating $(\mathbf{O})$ and quiescent $(\boldsymbol{\square})$ spheroids was plotted as a function of incubation time and the data fitted by an exponential growth curve using non-linear least squares regression. Spheroids (O) were also grown for 10 days in medium to generate quiescence and then switched to full medium. Values represent mean \pm sem of $n=20$ spheroids obtained for each time point.

(b) DLD1 spheroids with diameters of $200-400 \mu \mathrm{m}$ were harvested and a total homogenate prepared as described in materials and methods. The homogenates were analysed by western immuno-blotting with detection of the metabolic regulator c-Myc and quantitated using Image J. Values represent mean \pm sem of $n=3$ independent spheroid preparations.

\section{Figure 2 Expression of markers for proliferation and quiescence in DLD1 spheroids}

Markers of proliferation (Ki67) and quiescence (p27 Kip1) were measured in proliferating $\left(\mathrm{TS}^{\mathrm{P}}\right)$ and quiescent $\left(\mathrm{TS}^{\mathrm{Q}}\right)$ DLD1 spheroids using immunohistochemistry. Sections $(5 \mu \mathrm{m})$ were counterstained with haematoxylin and the scale bar corresponds to $200 \mu \mathrm{m}$. The density of staining was quantified for Ki67 $(n=4)$ and p27 ${ }^{\text {Kip1 }}(n=5)$ from multiple independent sections. Panel contents are indicated below:
(a) $\quad \mathrm{TS}^{\mathrm{P}}$ stained for the proliferation marker Ki67
(b) $\quad \mathrm{TS}^{\mathrm{Q}}$ stained for the proliferation marker Ki67
(c) Quantitation of Ki67 staining density in $\mathrm{TS}^{\mathrm{Q}}$ and $\mathrm{TS}^{\mathrm{P}}$ 
(d) TS $\mathrm{T}^{\mathrm{P}}$ stained for the quiescence marker p27 Kip1

(e) $\quad \mathrm{TS}^{\mathrm{Q}}$ stained for the quiescence marker p27 Kip1

(f) Quantitation of $p 27^{\text {Kip1 }}$ staining density in $\mathrm{TS}^{\mathrm{Q}}$ and $\mathrm{TS}^{\mathrm{P}}$

The $p$-values in the panels were obtained from two-tailed Student's t-test analyses.

\section{Figure $3 \quad$ Metabolite utilisation by proliferating and quiescent DLD1 spheroids}

The utilisation, or appearance, of metabolic fuels was measured for spheroids grown under conditions for proliferation or quiescence. In all cases, the values correspond to mean \pm sem from independent spheroid preparations and were compared using a Student's t-test with the P-values shown. All parameters were normalised to the total protein amount $(\mathrm{mg})$ in the spheroids.

(a) Glucose concentration in the culture medium was measured over a 24-hour period and the reduction in concentration was used to ascertain the rate of depletion by quiescent (white bar) $(\mathrm{n}=5)$ or proliferating (black bar) $(\mathrm{n}=7)$ spheroids.

(b) Lactate concentration in the culture medium was measured over a 24-hour period. The appearance of lactate in the medium is shown for quiescent (white bar) $(n=5)$ or proliferating (black bar) $(n=5)$ spheroids.

(c) Glutamine concentration in the culture medium was measured over a 24-hour period for spheroids grown in quiescent (white bar) $(\mathrm{n}=4)$ or proliferating (black bar) $(\mathrm{n}=5)$ spheroids.

\section{Figure 4 Metabolism of ${ }^{13} \mathrm{C}$-glucose by proliferating and quiescent DLD1 spheroids}

Proliferating $\left(\mathrm{TS}^{\mathrm{P}}\right)$ and quiescent $\left(\mathrm{TS}^{\mathrm{Q}}\right)$ tumour spheroids were incubated with $\left[{ }^{13} \mathrm{C}_{6}\right]$ glucose and cellular metabolites were extracted as described in materials and methods. Relative levels of metabolites and the enrichment with $\left[{ }^{13} \mathrm{C}\right]$ was 
determined using GC/MS analysis. The data in the schematic show the extent (\%) of $\left[{ }^{13} \mathrm{C}\right]$-label enrichment into selected intermediates from glycolysis and those derived from pyruvate. Data was obtained from $n=3-4$ independent preparations of spheroids in each case. Each histogram displays enrichment data for proliferating (black bar) and quiescent (white bar) spheroids.

\section{Figure $5 \quad$ Mass isotopomer analysis of selected metabolites}

$\mathrm{TS}^{\mathrm{P}}$ and $\mathrm{TS}^{\mathrm{Q}}$ were incubated with $\left[{ }^{13} \mathrm{C}\right]$-labelled fuels for $24 \mathrm{hr}$ and cellular metabolites were extracted for GC/MS analysis. Following incubation with $\left[{ }^{13} \mathrm{C}_{6}\right]$ glucose the fractional distribution of mass isotopomers was determined for (a) lactate and (b) citrate. Similarly, the fractional distribution of mass isotopomers following $\left[{ }^{13} \mathrm{C}_{5}\right]$-glutamine exposure were determined for (c) fumarate and (d) citrate. Each histogram displays data from proliferating (black bar) and quiescent (white bar) spheroids. Panel (a) also shows the distribution of isotopomers in the absence of any $\left[{ }^{13} \mathrm{C}_{6}\right]$-glucose (hashed bars).

Figure 6 Enrichment of ${ }^{13} \mathrm{C}$-label into TCA cycle intermediates and aminoacids from ${ }^{13} \mathrm{C}$-glucose in proliferating and quiescent $D L D 1$ spheroids

Proliferating and quiescent spheroids were incubated with $\left[{ }^{13} \mathrm{C}_{6}\right]$-glucose and cellular metabolites were extracted as described in materials and methods. Relative levels of metabolites and the enrichment with $\left[{ }^{13} \mathrm{C}\right]$ was determined using $\mathrm{GC} / \mathrm{MS}$ analysis. The data in the schematic show the extent (\%) of $\left[{ }^{13} \mathrm{C}\right]$-label enrichment into selected amino-acids and intermediates from the TCA cycle. Data was obtained from $n=3-4$ independent preparations of spheroids in each case. Each histogram displays enrichment data for proliferating (black bar) and quiescent (white bar) spheroids and significant differences are shown (Student's t-test).

Figure $7 \quad$ Metabolism of ${ }^{13} \mathrm{C}$-glutamine by proliferating and quiescent tumour spheroids 
Proliferating and quiescent spheroids were incubated with $\left[{ }^{13} \mathrm{C}_{5}\right]$-glutamine and cellular metabolites were extracted as described in materials and methods. Relative levels of metabolites and the enrichment with $\left[{ }^{13} \mathrm{C}\right]$ was determined using $\mathrm{GC} / \mathrm{MS}$ analysis. The data in the schematic show the extent $(\%)$ of $\left[{ }^{13} \mathrm{C}\right]$-label enrichment into selected TCA cycle intermediates, amino-acids and fatty-acids. Data was obtained from $n=3-4$ independent preparations of spheroids in each case. Each histogram displays enrichment data for proliferating (black bar) and quiescent (white bar) spheroids and significant differences $\left(\mathrm{P}<0.05\right.$, t-test) are shown $\left(^{*}\right)$. 
(a)

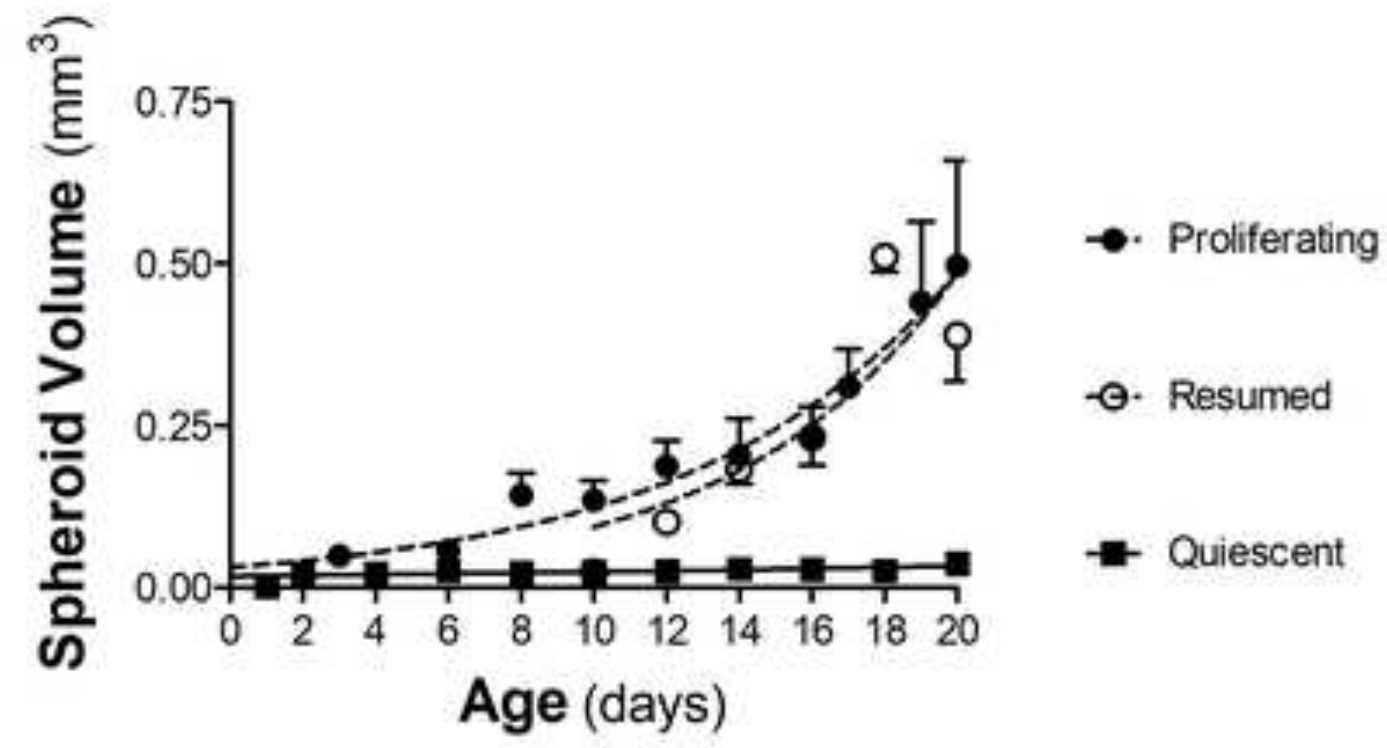

(b)

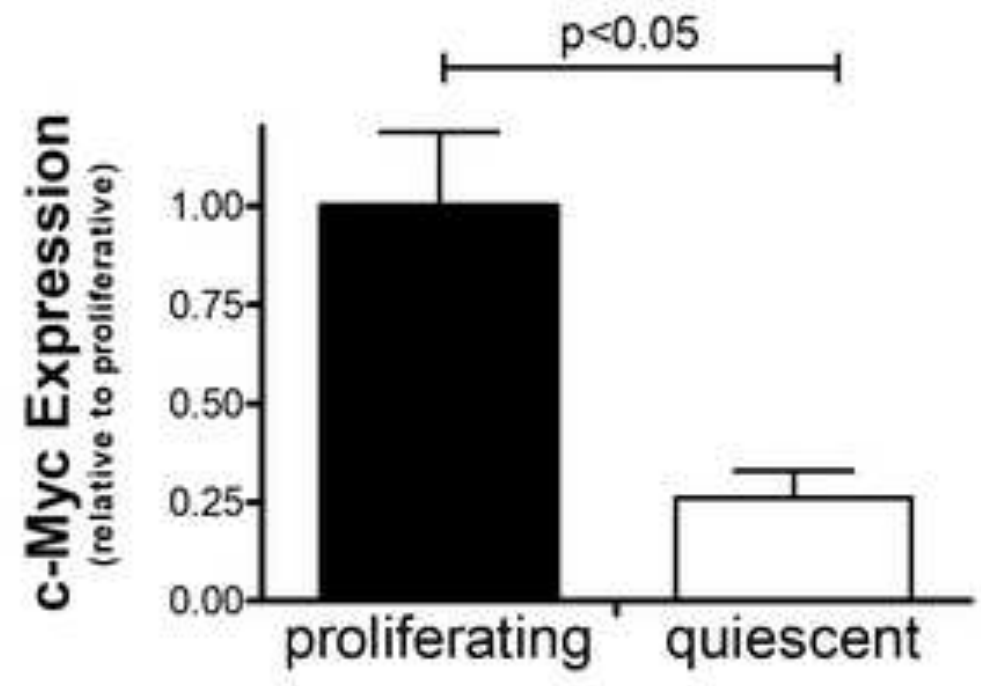




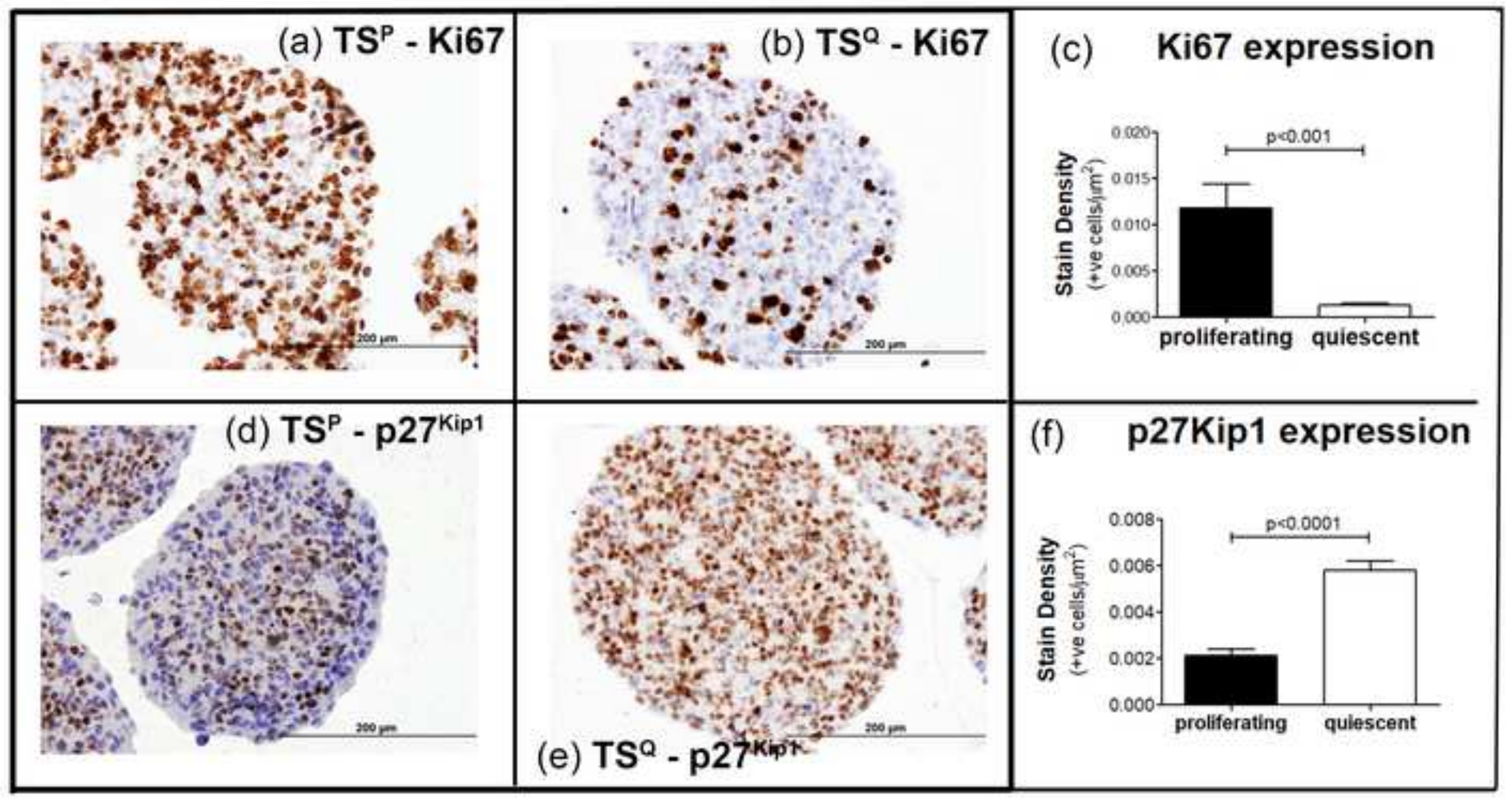


(a)

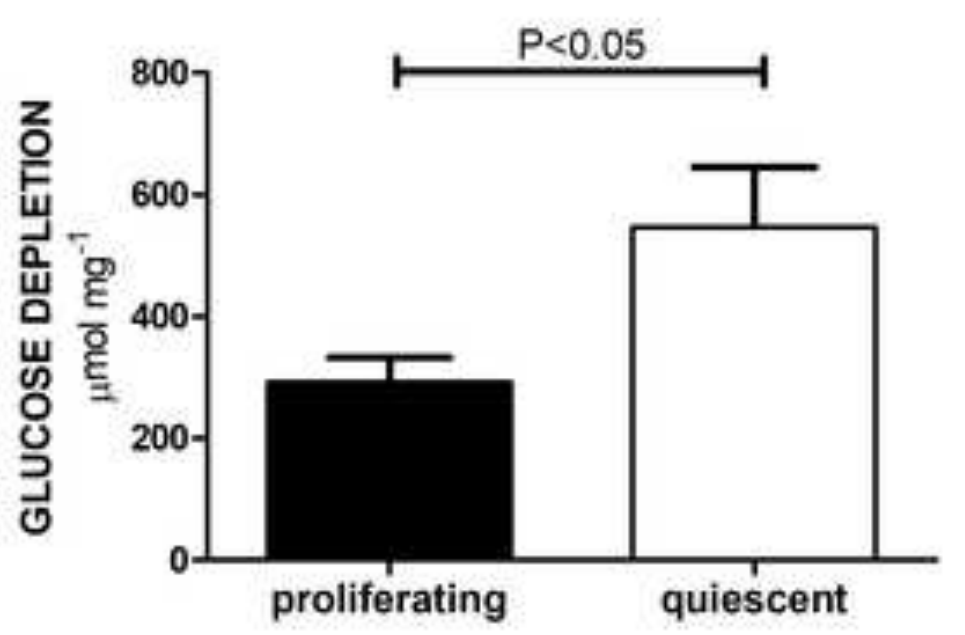

(c)

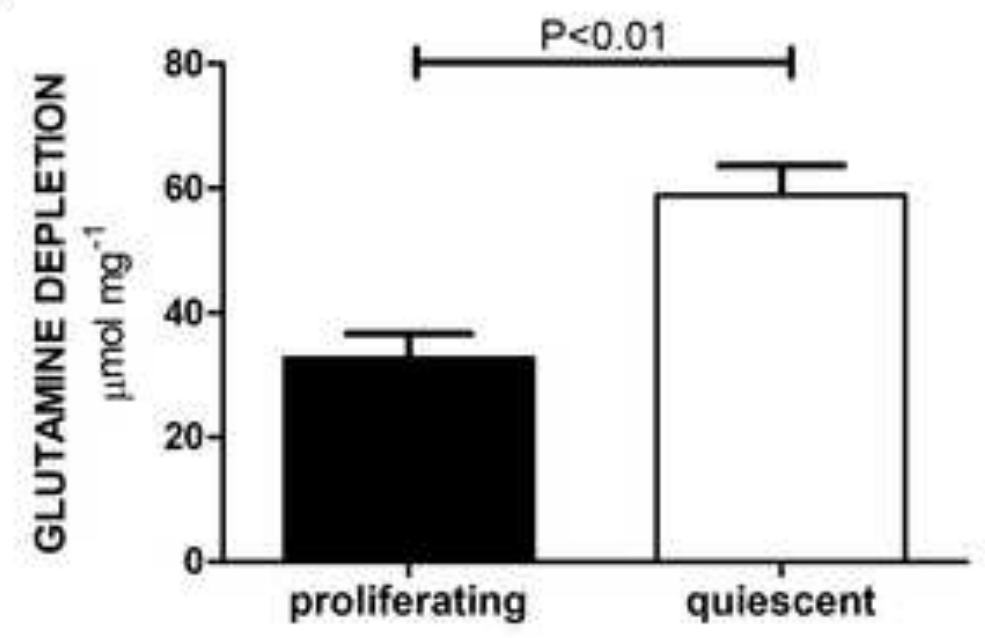

(b)

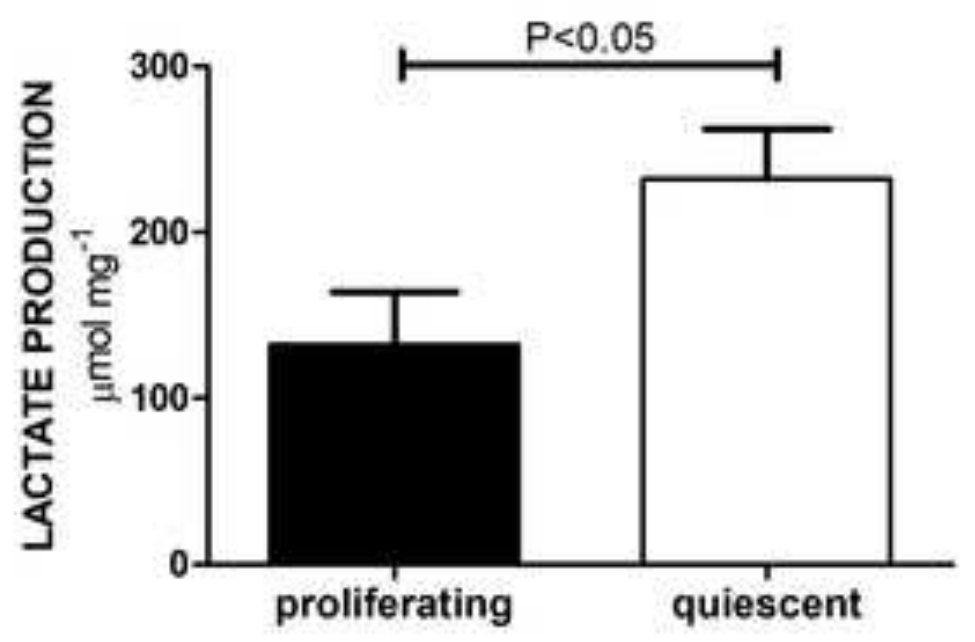

Figure 3 
${ }^{13} \mathrm{C}$-glucose metabolism

Figure 4

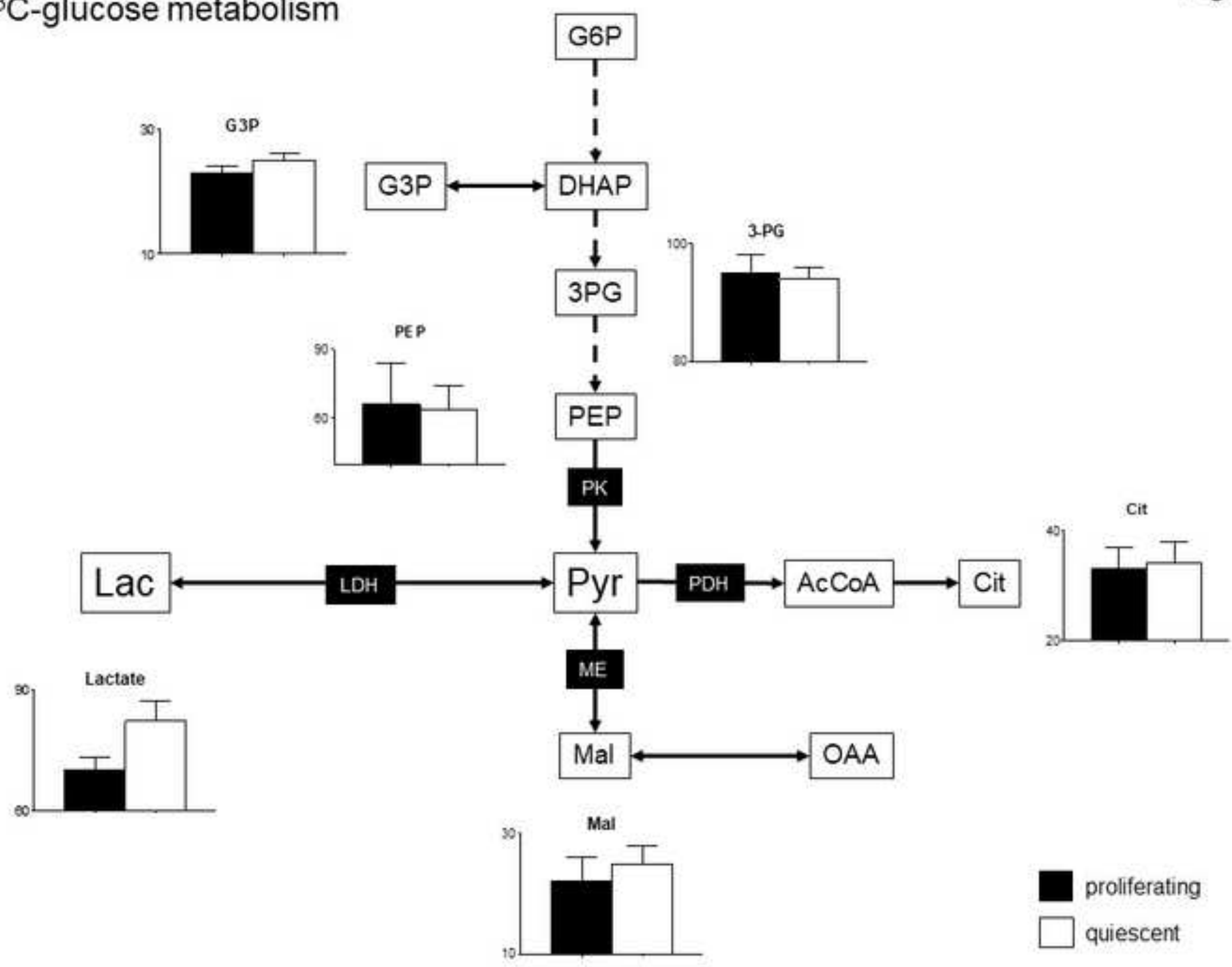




\section{Figure 5}

(a)

${ }^{13} \mathrm{C}$-glucose - lactate

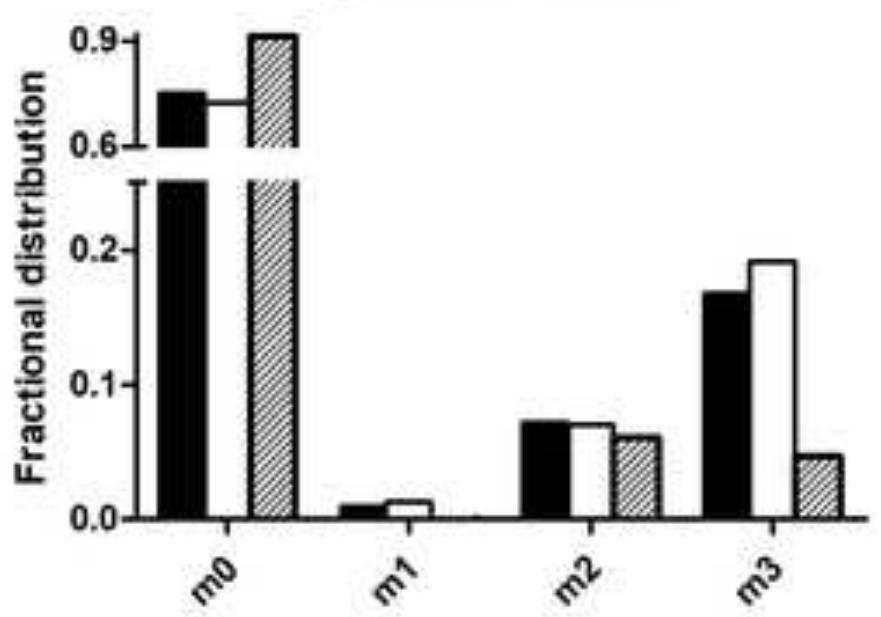

(c)

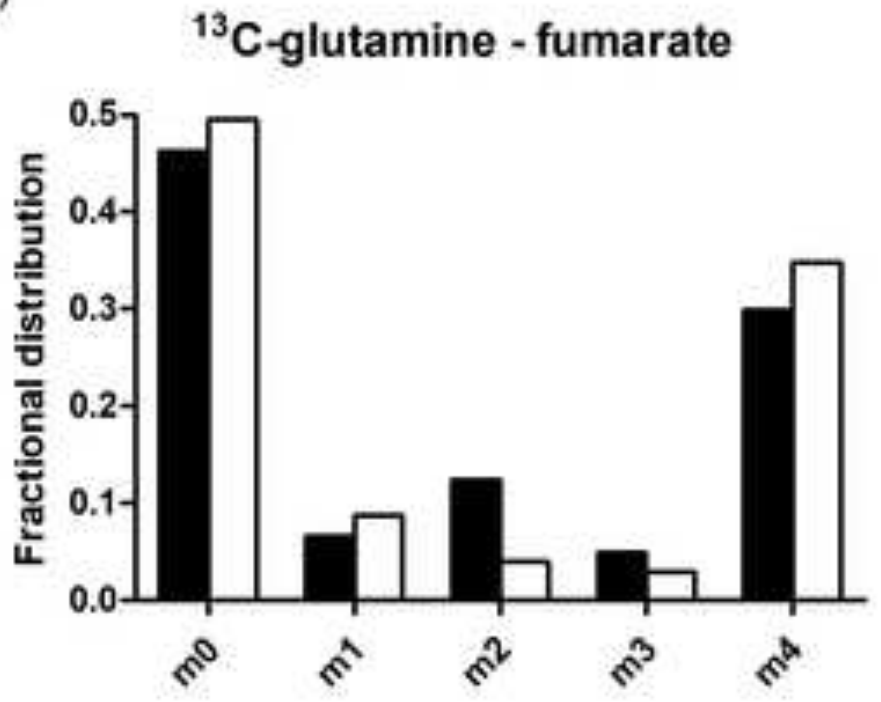

(b)

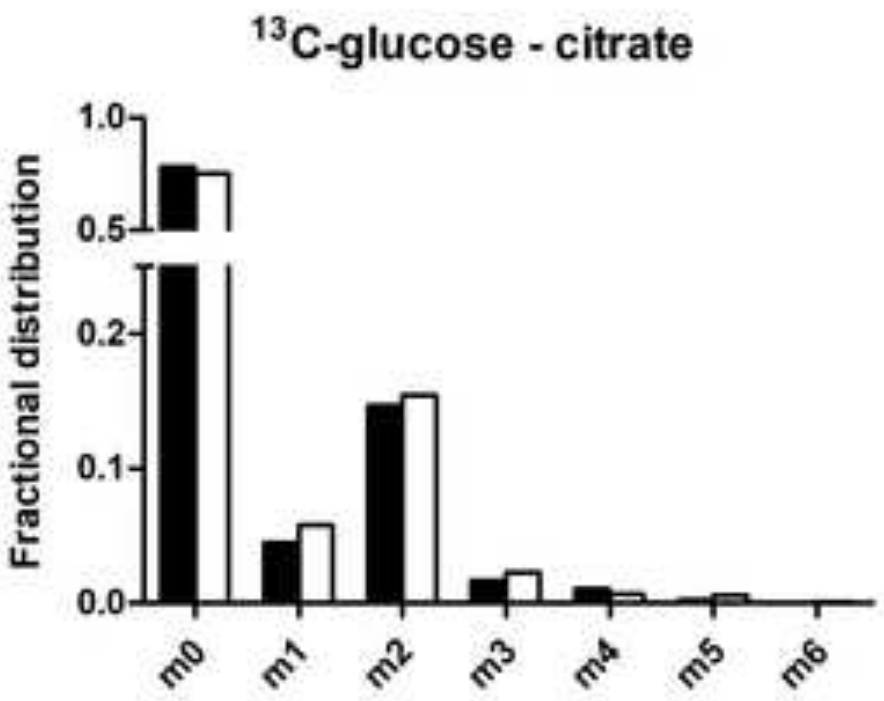

(d)

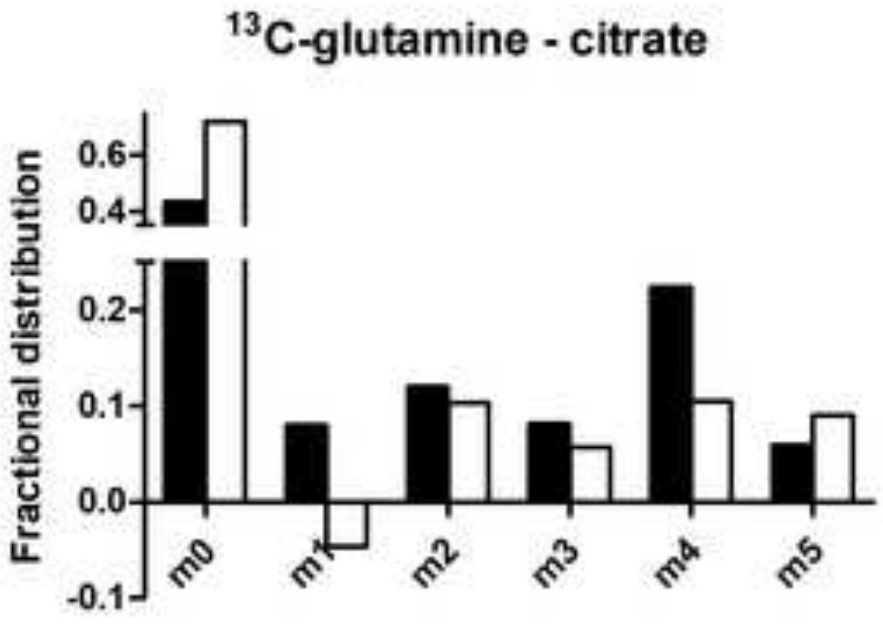


Click here to access/download;Figure(s);Figure 6_13Cglucose diagram TCA.jpg $\underline{\underline{ }}$

Figure 6
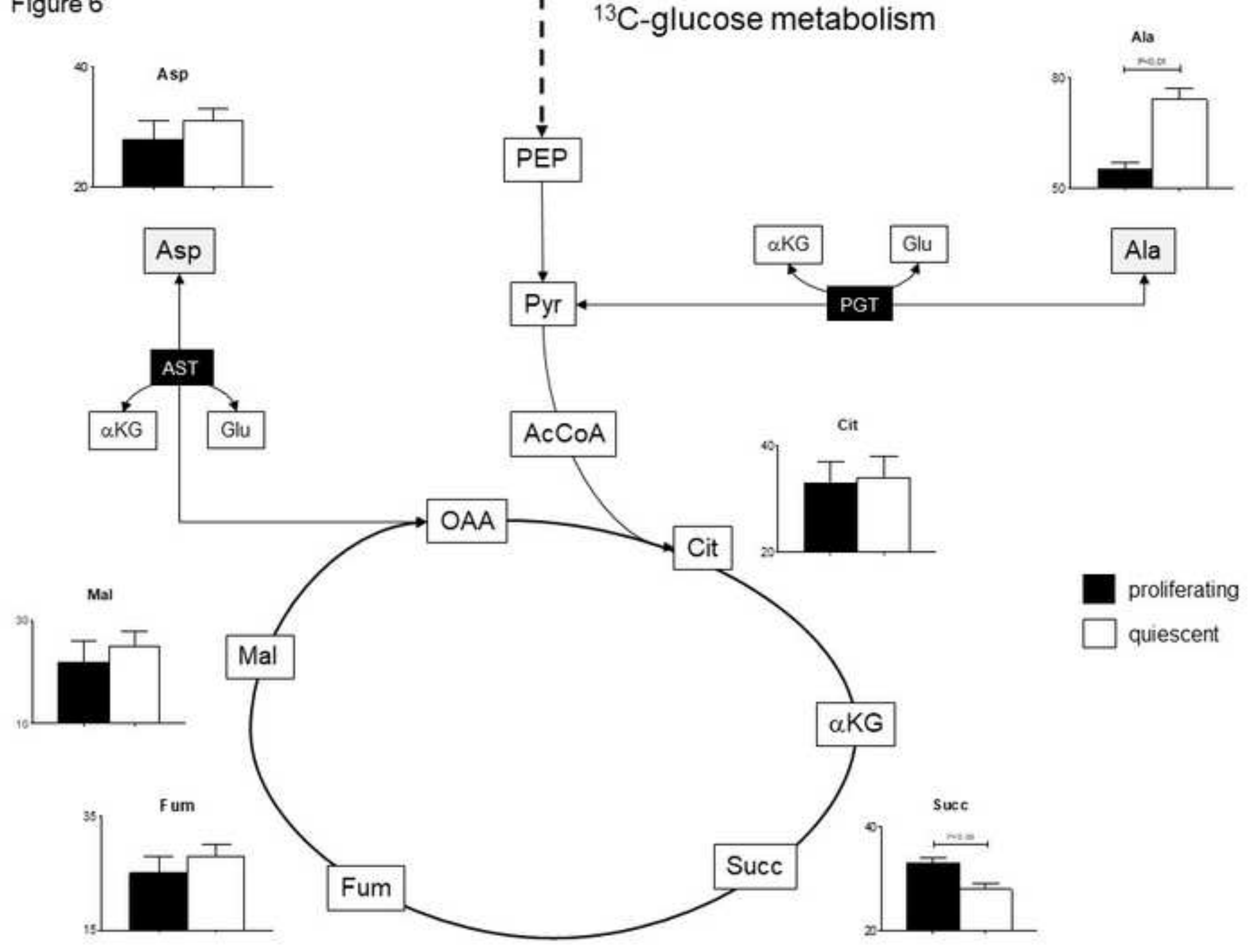

proliferating

$\square$ quiescent

Ala

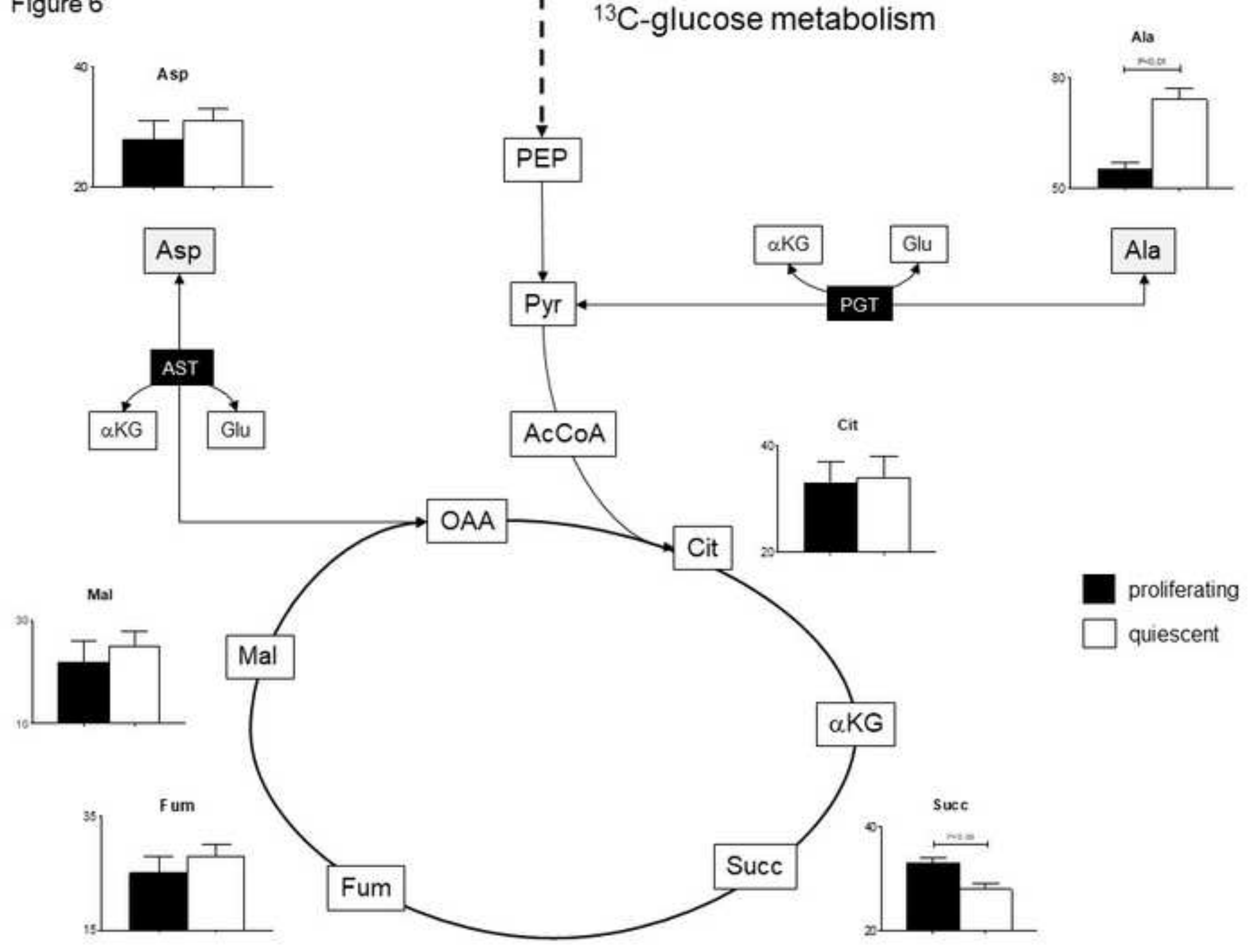

Figure 


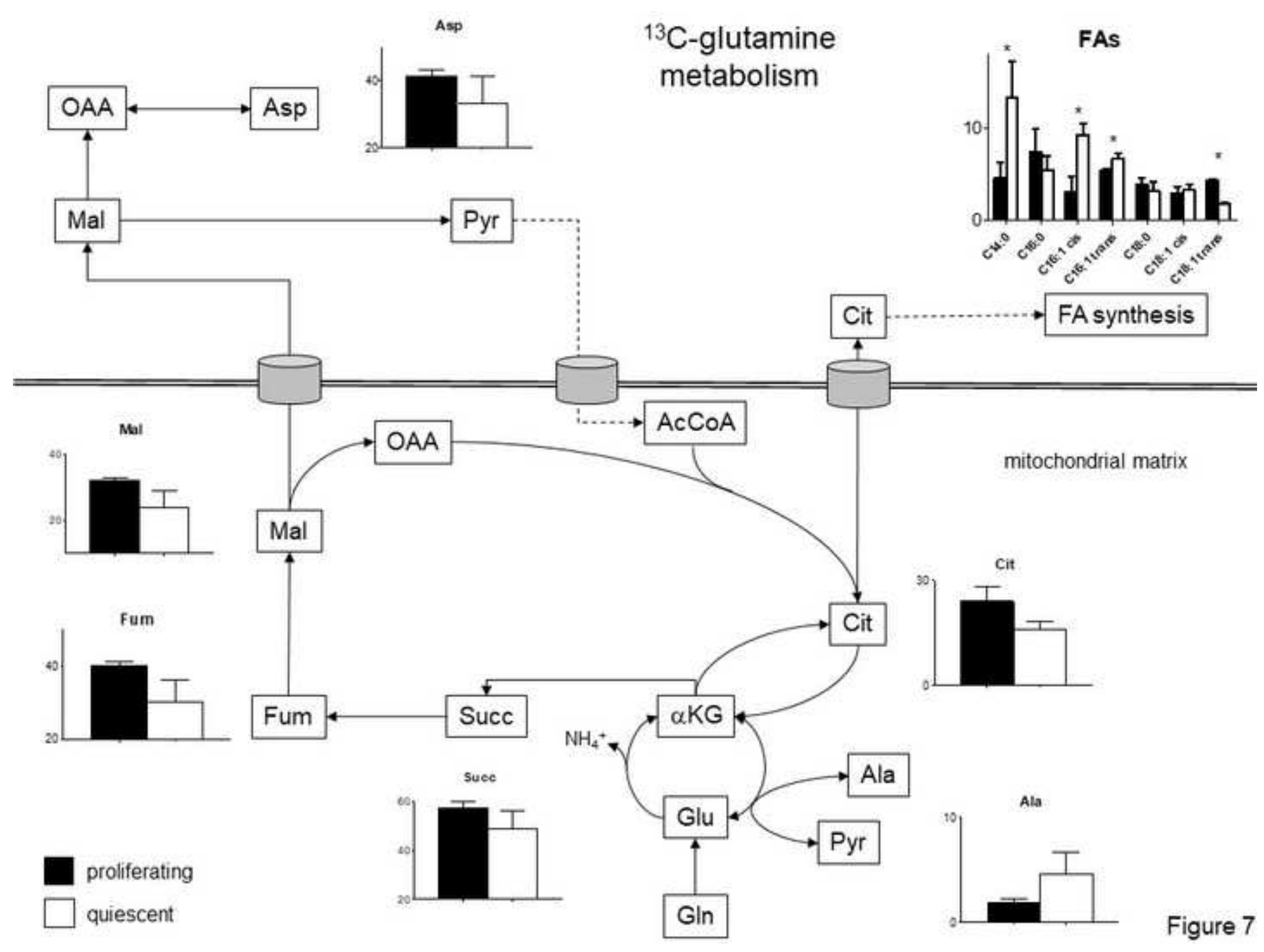


Click here to access/download Supplementary Files

IJBCB_SUPP data_revised v2.docx 
Hannah Smith, methodology, formal analysis, investigation, writing - review \& editing; David De Souza, conceptualisation, methodology, investigation, writing original draft; Dedreia Tull, resources, writing - review and editing; Malcolm McConville, resources, supervision, writing - review and editing, validation; Andrea Pellagatti, methodology, formal analysis, investigation, writing - review \& editing Jacqueline Boultwood, resources, supervision, writing - review and editing, validation; Mary Board, resources, investigation, supervision, writing - review and editing, \& Richard Callaghan, conceptualisation, methodology, resources, validation, supervision, writing - review and editing, project administration and funding acquisition. 
Declaration of Interest Statement

\section{Declaration of Interest Statement}

The authors declare that they have no competing interest with the contents of this article. 